\title{
APROXIMACIÓN AL FENÓMENO DE LA PINTURA ESQUEMÁTICA RUPESTRE EN LA SUBBÉTICA CORDOBESA. EL ABRIGO DEL TAJO DE ZAGRILLA (PRIEGO DE CÓRDOBA)
}

\author{
Rafael CARMONA A VILA (*) \\ Ignacio MUÑIZ JAÉN (**)
}

En memoria de Manolo "Dúrcal"

Sin duda alguna, una de las manifestaciones culturales más interesantes de la prehistoria peninsular post-paleolítica es el denominado, quizás imprecisamente, arte rupestre esquemático.

En el presente artículo vamos a dar a conocer un nuevo grupo pictórico localizado, geográficamente, en el ámbito de la sierra subbética cordobesa.

\section{Intenciones}

El trabajo que aquí presentamos es el preludio de otro futuro, más exhaustivo, que pretenderá estudiar la pintura esquemática en la subbética cordobesa, a partir de la revisión de las pinturas existentes, la prospección intensiva de la pared rocosa que nos ocupa y la puntual en otras zonas, así como laprospección arqueológica del entorno de las pinturas y el estudio geográfico del mismo. Todo con el propósito de intentar comprender, a escala regional, un fenómeno complejo y sugerente pero falto, en gran parte, de una explicación aproximativa.

A escala regional porque creemos en la mayor posibilidad de entendimiento del problema si recurrimos al marco concreto de una zona más o menos homogénea, sin intentar buscar una respuesta general, globalizadora, pero sin caer tampoco en un particularismo reduccionista de base local, que nos impediría aclarar algo la situación.

(*) Museo Histórico Municipal de Priego de Córdoba.

(**) Universidad Complutense de Madrid, 
De este modo, una vez analizada la zona tratada nos permitiría relacionarla con otros ámbitos y así poder acercarnos a la comprensión global de este fenómeno.

Para todo ello se partirá de unos planteamientos teóricos-metodológicos, así como de una revisión crítica de los trabajos realizados hasta la fecha en el campo de la pintura esquemática, queesbozamos ya en el presente artículo, al igual que la hipótesis de partida, mejor definida y ampliable y veríficable, o no, en el trabajo posterior.

\section{IL Planteamiento teórico}

La necesidad de poseer un corpus teórico-metodológico, un metalenguaje o epistemología en Prehistoria, es fundamenta] para que ésta pueda ser considerada como ciencia. Investigación prehistórica que "debe ser concebida como una operación científica de carácter recíproco -un proceso dialéctico- guiado por la teoría y controlado por los hechos" (MARTIN DE GUZMAN, 1981:60).

Mas entrar en la importancia de la Teoría en la Prehistoria no es nuestro cometido (nos remitimos, por ejemplo.a VICENTGARCIA, 1983; MARTÍNEZ NA VARRETE, 1989: 1-108), únicamente queremos, por una parte, subrayar la necesidad de la definición teórica-metodológica desde el comienzo de la investigación, explícitamente, y no expresarla de forma subliminar, inconsciente, implícitamente, con el propósito de "conocer las alternativas existentes y decidir entre ellas, de manera consciente" (MARTÍNEZ NAVARRETE, 1989: 19).

Creemos que es una aportación primera y fundamental que facilita la "apertura de discusión no dogmática" (VICENTGARCIA, 1981:86). Intentar, además, que esa definición sea coherente con los datos arqueológicos que maneja y que evite crear * 'mitos", para locual,el investigador "tiene el deber de ser escépticorespecto de su propio trabajo, si se atreve, y escéptico de el de los demás, para ver a donde no va y para no terminar creando (esos) mitos*' (RENFREW, 1988:96).

Por otra parte, indicar que el debate teórico que está abierto en España no consideramosqueseaintenso, como a veces se le califica, sino que, por el contrario, creemos que es escaso e insuficiente y, en cualquier caso, necesario como vía de normalización. Normalización ya conseguida, desde hace tiempo, en otros países, sobre todo anglosajones, que no precisan de nuestras nuevas preocupaciones.

Por nuestro lado, partimos de un planteamiento teórico general materialista histórico aunque no en su acepción plenamente determinista, es decir, consideramos que "la cultura es un fenómeno superorgánicoque sigue leyes, noqueridas por los individuosque participan en la misma, sino inherentes a ella" (MARTÍNEZ NA VARRETE, 1989:115).

Pero ahora no debe entenderse como la creencia en la certeza causa-efecto sino, más bien, en la probabilidad causa-efecto, siguiendo el "principio de indeterminación" de 
Heisenberg que se aplica atecas las ciencias modernas y que deja espacio a otras variables causales distintas de la principal.

Además, el factor económico no seria el único determinante del proceso histórico, hecho ya defendido por Engels, aunque sí el que lo definiría en último lugar.

Nos encontramos ante una' 'casualidad negativa", "ya que se determina prioritariamente lo que no puede suceder frente a lo que tiene que suceder" (MARTÍNEZ NA V ARRETE, 1989: 116) o dicho de otra forma, en palabras del propio Engels: "Según una comprensión materialista de la Historia el momento decisivo en el proceso histórico como un fenómeno definido es, en última instancia, la producción y la reproducción de la vida real. Ni Marx ni yo mismo afirmamos nunca nada mas allá. Si alguno tergiversa esta opinión, manteniendo que el factor económico es irrevocablemente el único factor determinante, la reduce a una frase abstracta sin significado alguno". (Cit. en ALÓN A FRANCH, 1989:91).

De este modo, la aceptación de esta variabilidad nos va a permitir tener en consideración otros condicionantes.

En cuanto a ideología y simbología, se hace preciso tomar una postura por nuestra parte, debido ala evidente relación con el Arte y, en este caso, con las pinturas esquemáticas.

Evidentemente, no creemos que la ideología sea la explicación a las transformaciones sociales, como sostienen tos seguidores de la "Arqueología Contextual" (a cuya critica nos remitimos a: RUIZ, CHAPA, RUIZ ZAPATERO, 1988). sin embargo, los rituales y el simbolismo en la pintura esquemática, con un repertorio muy estable de motivos abstractos y de gran longevidad, puede considerarse, siguiendo a Bloch, como una forma especial de comunicación que retiene su significado durante un largo periodo (BLOCH, 1989) y, como opina Bradley, la ideología que subyace a estas simbologías (se pudo) emplear para fortalecer los lazos entre población y los recursos naturales de los que vivía (BRADLEY, 1987).

Así, reconocemos esta dualidad en la cultura: una dimensión tecno-económica, adaptativa y, otra, imaginaria o mental, es decir, como sostiene Criado Boado, y en reíación con la "Arqueología Espacial", una "bidimensionalidad" (CRIADO BOADO, 1990) materia y concepto, conceptualización que, aunque en Arqueología no fuese posible "reconstruiroavistar...ese obstáculo no debería ser un argumento suficiente para olvidar que esas conceptual i zac iones existieron y que fueron elementos fundamentales en la articulación de cada cultura con su entorno" (Ibidem, 1980:66).

No obstante, el margen de maniobra de la ideología lo vemos limitado, limitación que produce el propio cambio ideológico, que se adapta" a las exigencias de reducir costos y maximizar beneficios en la lucha, para evitar que los modos de vida decayeran" (MARVIN HARRIS. 1987:190).

De este modo, en la influencia mutua entre economía e ideología "la fuerza que hasta ahora han ejercido entre sí no es semejante' ${ }^{1}$ (Ibidem, 1987:190). 
El reconocimiento de este margen también nos lleva a considerar y aceptar procedimientos de otra orientación teórica como es el Estructuralismo.

El Estructuralismo ha dirigido sus trabajos principalmente hacia el Arte o lo decorativoy el campo más apropiado para su utilización es el "análisis formal", en la búsqueda de posibles significados deese lenguaje (como consideran la pintura prehistórica), de sus palabras.

Como nos dice Martín de Guzmán: "Abordar lecturas" o las interpretaciones estructuralistas ya no de los "objetos" y de sus "discursos", sino del "totum revolutum" de la "apariencia" cultural, obligaría a introducir, y a explicar, uno de los recursos que más éxito ha proporcionado en los análisis lingüísticos y antropológico, en general, como lo es el' 'sistema de signos". Así elevar los "objetos" a signos es reconocer, más allá de su función o valor, de su "clase", que todo artefacto es la unión resultante de un elemento materia] (significante) y de un componente funcional (significado)" (MARTIN DE GUZMAN, 1981:53).

Dentro del estudio de las pinturas esquemáticas este procedimiento ha sido seguido en varios trabajos, como veremos, en donde han empleado la semiótica como ciencia estructural y considerando así la pintura como una' 'escritura", un "lenguaje no verbal y artístico que el hombre utilizó para informar acerca de sus inquietudes y visión del mundo, con la colaboración de unos signos iconográficos, obviamente convencionales" (CASTAÑEDA, CARRASCO RUS, 1979:62).

Nosotros consideramos positivamente esta aportación. El problema será descodificar el mensaje, y para ello se hace preciso contextualizar los indicadores arqueológicos a partir de asociaciones y dicotomías, conviniéndoles en "indicadores primarios" o de asociación evidentey "secundarios" o de asociación no tan evidente (como nos recuerda MARTIN DE GUZMAN, 1981).

Más adelante insistiremos en este tema aplicado a nuestro caso.

Con lo dicho hasta ahora es posible que se nos pueda tachar de "eclécticos" pero creemos, con Alcina Franch, que es posible un entendimiento en este sentido (ALONA FRACH. 1989: 112).

Por último, queremos señalar las limitaciones a las que se enfrenta la Prehistoria y máxime al abordar el mundo, muchas veces ingrato, del arte, pero observando, al mismo tiempo, qué limitaciones existen en todas las ciencias.

Limitaciones que empiezan con la propia subjetividad del investigador ya que como dice Pilbeam: "no vemos las cosas como son, las vemos como somos nosotros" (Cit. en LEWIN, 1989:40), "cosas" que reflejan nuestra sociedad y cultura y así, como decía Spengler: "el conocimiento científico no es más que una creación cultural entre otras" (Cit. en THUILLER, 1989: 432) condicionado, de este modo, por factores "intemalistas" o propios de laCienciay' 'extemalistas" o sociales, políticos, religiosos, etc. (como nos recuerda MARTÍNEZ NAVARRETE, 1989: 1). 
Mas, ciertamente, lo criticable no es tanto la presencia de ese subjetivismo cuanto la falta de reconocimiento del mismo.

Creemos en la conveniencia de partir y reconocer esta dificultad generosamente, para no dar por tajante e inmutable una teoría, crear' 'argumentos de autoridad" y tradiciones académicas que, una vez implantadas, confieren al intento de cambio la situación de una "circunstancia heroica" (MARTÍNEZ NAV ARRETE. 1989: XVII).

Por tanto, los inconvenientes y dificultades de los que se parten, dados muchas veces por obvios y presentes, sin esa reflexión, quedan como afirmaciones categóricas, voluntarias o no, afirmaciones que convierten a las hipótesis en dogmas que retrasan la invest gación y "aletargan" la ciencia. Yes que, en palabras de Washbum: "una vez que uno cuenta, entre comillas, con una teoría científica, en mayúsculas, se crea una fuerte resistencia al cambio" (Cit. en LEWIN, 1989:33).

Este punto es importante dada la influencia del lenguaje sobre el lector y, también, sobre el propio autor que, a través de metáforas y comparaciones, empuja hacia su terreno el propio estudio y las conclusiones que, sobre éste, extrae el receptor de la obra. En este sentido, y como afirma Landau: "las metáforas ejercen una poderosa influencia, no sólo enlavidacorrientesinoenlaciencia"(Cit. en LE WIN, 1989:36) y además nos descubren la carga ideológica del investigador ya que "las cuestiones semánticas afectan a los contenidos conceptuales" (MARTÍNEZ NAV ARRETE, 1989: XIV).

Con todo lo dicho no se pretende llegar a un callejón sin salida, a un subjetivismo sin solución, sino considerar, como lo hace Shennan, que algo es cierto o falso dependiendo de las categorías de certeza y falsedad que tengamos (SHENNAN, 1989) y en cualquier caso sostener, al lado de Duvignaud, que la Arqueología, al igual que la Sociología, "debe alcanzar una explicación, pero que esta explicación sigue siendo una hipótesis" (Cit. en CRIADO BOADO, 1990:65)y siempre, como opina Johanson: "es preferible debatir el problema sin resolverlos que resolverlo sin debatirlo" (Cit. en LEWIN, 1989:51).

Con el reconocimiento de estas limitaciones, adoptamos nuestra teoría que, como ya se ha dicho, se mueve dentro de un marco definido, pero amplio y elástico.

\section{Revisión historiográfíca}

En este apartado queremos abandonar la introductoria visión historiográfíca acrítica por otra reflexiva, aunque sin profundizar en exceso dado el carácter del artículo.

Vamos a referimos, sobre todo, a los trabajos realizados en Andalucía, aunque no olvidaremos otros más generales, revisando las distintas tendencias teóricas, que se entrecruzan en la historiografía y no siguen una evolución cronológica.

Antes de comenzar queremos puntualizar y repetir que, apesar del carácter interpretativo difícil, ingrato y, si se quiere, poco esclarecedor de la información extraible del 
estudio de las pinturas, de su significado y función, no podemos por ello menospreciar u olvidar acercarnos a su estudio con unos planteamientos teóricos departida, junto con una hipótesis que, como hemos dejado ya expresado, es necesario para considerar la Prehistoria como ciencia.

Decimos esto, de nuevo, porque en la investigación sobre pintura esquemática, estos planteamientos de partída han brillado por su ausencia, en la gran mayoría de los trabajos. En este sentido, siguiendo a Martínez Navarrete, no ha habido investigación prehistórica sino arqueológica o taxonomía de carácter empírico y descriptivo dentro de un ' 'positivismo clásico" (MARTÍNEZ NAVARRETE, 1989).

De este modo, nos enfrentamos a la corriente que ha tomado Martínez Navarrete como "Anticientifista" (Ibidem, 1989)o "ciclo tradicional" (VICENT GARCÍA, 1982), dentro del "ciclo nomotético" de "concepción normativista".

El inductivismo aplicado por esta tendencia, posee un empirismo exacerbado, una intención acumulativa de datos y evidente subjetivismo, no admitido muchas veces, especialmente en la cronología.

Esta corriente rechaza la Teoría acudiendo a la oposición entre pensamiento humanista y científico aunque, como ya apuntamos, la ideología se oculta bajo la terminología y se delata.

Además, esta corriente es muy dada a construir "argumentos de autoridad" (no exclusivamente ella, bien es cierto) sobre datos muy débiles, sostenidos en paralelismos, lo que provoca el cambio de teoría cuando los datos se modifican o, a lo peor, que se busquen justificaciones "ad hoc" utilizando paralelos más lejanos.

La periodización interna en estos trabajos es fundamental y se convierte "no en intrumento de la investigación sino en uno de sus fines" (MARTÍNEZ NAVARRETE, 1989:139), y siempre seguido de un "criterio esteticista" que juzga el progreso por el más o menos esquematismo y simplificación, guiados por los "ciclos" impuestos por la escuela del P. Schmidt.

Dentro de esta corriente, podemos distinguir diferentes posturas ante lacronología de las pinturas: las derivadas del contexto arqueológico, laque lo hace por paralelos o la que toma la evolución estilística como criterio. Las tres posturas no, necesariamente, se excluyen y tienen como referencia al Arte Levantino.

Algunos de los trabajos que consideraron el contexto arqueológico e incluso prospectaron la zona circundante al abrigo/s son los de: CABRÉ y HERNÁNDEZ PACHECO, 1914; GARCÍA SÁNCHEZ y SPAHNI, 1958; SPAHNI y GARCÍA SÁNCHEZ, 1958; GARCIA SÁNCHEZ y PELLICER, 1959; CARRASCO RUS, 1981 a,b,c, 1981; JORDA 1982; MÁRQUEZ ROMERO y MORALES MELERO, 1985; MARTI I CORNELLA, 1986-87, Todos coinciden en un origen neolítico y desarrollo en el Eneolítico, siendo Carrasco Rus quien baja el origen hasta un Neolítico antiguo.

Algunos de los trabajos que situaron la cronología de las pinturasen un Neolítico pero 
únicamente basándose en consideraciones estilísticas son los de: BREUIL y BURKITT, 1929; OBERMAIER. 1916; BREUIL, 1933 (con origen en el Epipaleolítico); BOSCH GIMPERA, 1965. Otros abrigos fueron considerados como neolíticos, por el estilo de sus pinturas, en los estudios de: DAMS, 1979; GARCÍA y SÁNCHEZ, 1979).

Una tercera vía, "más de gabinete, en donde todo lo oriental adquiere una gran efervescencia, predominando un di fu sionismo a ultranza... ignorándose todo lo local o considerándolo como un reflejo de lo de fuera, quedando reducido a meras comparaciones con los lugares más exóticos y distantes" (CARRASCO RUS et alii, 1985: 128) engloba una serie de trabajos que, obsesivamente, clasifican las pinturas esquemáticas dentro del Bronce I; sin definir qué significa ese B: I, y haciéndolas relacionar con la llegada de "prospectores de metales" del Próximo Oriente.

Algunos trabajos que sugieren lo anterior son los de: KÜHN, 1957; ACOSTA, 1968; GONZÁLEZ NAVARRETE, 1971; RUBIO DÍAZ, 1976; BARROSO RUIZ, 1980; DAMS, 1980; LÓPEZ PAYER y SORIA LERMA, 1980. 1984-85; SANCHIDRIAN TORTI, 1982; RIPOLL 1982; MARTÍNEZ GARCÍA, 1984-85; BELTRAN, 1989; RAMOS et alii, 1989. Los trabajos de BERN1ER y FORTEA, 1968-69; BERNIER et alii, 1981, sitúan la cronología en el Bronce I debido a la aparición cercana de cerámica a la almagra, en clara incongruencia.

A esta situación, pensamos que se ha llegado por lo siguiente:

- Dependencia y referente estilítico en el Arte Levantino.

- Despreocupación por el contexto arqueológico de las pinturas.

- Desconocimiento del Neolítico en la zona andaluza.

- Fijación en la fecha de la cerámica de Millares, con motivos oculados, del 2345 a.c.

- Desconsideración de los paralelos en los motivos presentes en cerámica neolítica.

- Determinismo tecnológico.

- Difusionismo a ultranza.

La evolución estilística de lo naturalista a lo esquemático, con valor cronológico, no lo aceptamos, ya que estos diferentes estilos, el Arte Levantino y la Pintura Esquemática, pudieron ser coetáneos o no, pero, en este último caso, no por una cuestión deestilo. A este respecto, recordar las importantísimas y abundantísimas representaciones esquemáticas en la pintura rupestre paleolítica, no por ello coetáneas con las nuestras.

La despreocupación por el contexto propio de la zona se hace evidente ya que, de no ser así, al menos en la zona subbética andaluza, se apreciaría su gran conexión con yacimientos calcolíticos y neolíticos, siendo además , estos últimos, procedentes de un sustrato anterior (ver ASQUERINO, 1987 a). Cuando se admite un origen calcolítico, relacionado con el Megalitismo, se acude al origen extemo del mismo, pero las investigaciones anglosajonas han concluido que el Megalistismo no es un hecho alóctono a la P. Ibérica y, además, que tiene sus raíces en el mundo neolítico (ver RENFREW, 1979).

La fecha del 2345 a.C. como bien dice Carrasco Rus (CARRASCO RUS et alii, 1985), 
se toma como origen de la pintura esquemática, en un contexto pre-campaniforme, pero debería señalar una fase dentro de su evolución.

En cuanto a los paralelos con motivos presentes en la cerámica neolítica, estos existen y son numerosos (como nos advierten de nuevo CARRASCO RUS et alii, 1985:144146): motivos en dientes delobo y zig-zags están incluidos en cerámica impresa e impresa cardial de "Carigüela", "Cueva del AguadePrado Negro", "las Majolicas", "Murciélagos", "Cerro Pandera"; antropomorfos en fragmentos cerámicos de "Cueva del agua de Prado Negro", "Sima LJ II"; soles impresos e incisos en fragmentos cerámicos de "Cueva Mujer", "Carigüela", "Malalmuerzo"; cuadrúpedo o motivo radiado en fragmentos cerámicos de "Cueva del Agua de Prado Negro", "Sima LJII"; soles impresos e incisos en fragmentos cerámicos de "Cueva Mujer", "Carigüela", "Malalmuerzo"; cuadrúpedo o motivo radiado en fragmento cerámico de "Sima de Conejo". A esto se le puede añadir las formas ramiformes pintadas en cerámica neolítica de "Mármoles" (ASQUERINO, 1985), el alisador neolítico con zoomorfo grabado de "Murcielaguina" (GAVILÁN, 1985), o las plaquetas grabadas con temas esquemáticos de "Mármoles" (ASQUERTNO, 1987b y GAVILÁN 1987). Todos estos ejemplos pertenecen a yacimientos situados en laSubbética andaluza siendo los de "Mármoles", "Murcielaguina", y "Murciélagos" los que se encuentran en la Subbética cordobesa.

Frente al determinismo tecnológico, sólo indicar la multitud de trabajos, tanto en España como en Europa, que reflejan la escasa importancia que tuvo la metalurgia durante el Calcoíitico e incluso Bronce inciai y medio, sin existencia de hornos (únicamente la cerámica-crisol) y de carácter familiar (algunos ejemplos, ver: ROVIRA, 1990; MARTÍNEZ NAVARRETE, 1989; Seminario sobre el Origen de la Metalurgia en la P. Ibérica, 1987; COLES y HARDDING, 1979; RENFREW, 1979).

El difusionismo a ultranza quedaría invalidado por la reflexión de los anteriores puntos.

Otra serie de trabajos son los que podríamos enmarcar en la denominación de "positivismo moderado" (según MARTíNEZ NAVARRETE, 1989). Serían trabajos que pretenden una observación minuciosa de los datos, con intención también acumulativa, surgidos de la "Arqueología Cuantitativa", con empleo de procedimientos estadísticos, pero ausentes de consideraciones teóricas. En los estudios sobre pintura esquemática, esta corriente no está muy definida pero se podrían incluir los de: BARROSO RUIZ, 1982; SORIA LERMA y LÓPEZ PAYER, 1982,86-87.

Por último, una escasa representación de trabajos que incluimos en la corriente "Cientifista o Neopositivista" (MARTÍNEZ NAVARRETE, 1989), que sigue el ciclo "nomotético" a partir de un método hipotético-deductivo con clara intención revisionistay crítica, representando un avance en estos estudios. Así pues, desde una óptica estructuralista, y aplicado a casos concretos, tenemos los trabajos de CASTAÑEDA y CARRASCO RUS, 1979; CARRASCO RUS y MEDINA CASADO, 1980; MARTÍNEZ 
GARCÍA, 1981. Desde la perspectivade la "ArqueologíaEspacial" MORALES MELERO, 1984, pone en relación las pinturas con su entorno arqueológico, del mismo modo que con relación a la función de las cuevas (cuando las pinturas se sitúan en ellas).

CARRASCO RUS, CARRASCO RUS, MEDINA CASADO y TORRECILLAS GONZÁLEZ, 1985 parten también del Estructuralismo, aunque ahora sin aplicación concreta, realizando una crítica historiográfica y una revisión cronológica.

Estos últimos trabajos recogen un conocimiento previo del entorno arqueológico y coinciden en un origen y desarrollo en el Neolítico y Calcolítico, con prolongación en la E. Bronce (los autores del último trabajo citado consideran no tener argumentos para prolongar, en su zona de estudio, el fenómeno esquemático hasta la E. del Bronce).

IV. El abrigo del tajo de Zagrilla

\section{I. Localización}

Las pinturas objeto de nuestro estudio, fueron descubiertas, de forma casual, a fines de Mayo de 1990, por Antonio Castro, vecino de la aldea de Zagrilla (Priego de Córdoba) en un abrigo natural de la pared rocosa conocida como "Tajo de Zagrilla" o "Tajo de las Tres"(1).

Este grupo es el tercero que se documenta, hasta hoy, en el término municipal de Priego de Córdoba pues, con anterioridad, se conocían las manifestaciones parietales esquemáticas de dos cavidades subterráneas de enorme interés arqueológico: Cholones (a escasa distancia del "'Tajo de Zagrilla") y Murcielaguina (en las Angosturas).

Las pinturas se encuentran al norte de la aldea de Zagrilla Alta, en una de las paredes rocosas que forman las estribaciones meridionales de Sierra Alcaide. La al tura aproximada sobre el nivel del mar es de $825 \pm 10 \mathrm{~m}$. y las coordenadas geográficas de la zona de su emplazamiento, según la hoja 989 (Lucena) del Mapa Topográfico de España E/I:50.000,

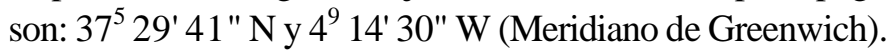

Como soporte para su trazado, se eligió un pequeño refugio u oquedad de la roca caliza, libre de la incidencia directa del agua de lluvia gracias a una pequeña cortina natural que la protege por su parte superior (cf. sección topográfica).

En sentido estricto, el abrigo posee unas medidas muy reducidas $(2,20 \mathrm{~m}$. de altura, $1,30 \mathrm{~m}$. de profundidad y 1,60 m. de anchura) aunque una cornisa rocosa, de sección

(1) Agradecemos las intermediaciones de Antonio Ballesteros y Agustín Ruiz-Ruano pues, éste último, puso el descubrimiento en conocimiento del Museo Histórico Municipal de Priego que pudo. así. corroborar ei interés arqueológico de las pinturas. Reconocemos, igualmente, la inestimable colaboración prestada por Domingo Campos y J.A. Castillo en los diferentes trabajos de registro científico de! abrigo. Por último, agradecemos a Manuel Pérez Urquizar, buen conocedor de las sierras prieguenses, los datos proporcionados sobre el entorno geográfico. 
irregular, se abre delante de él, aumentando las posibilidades espaciales del lugar. Los accesos a las pinturas son imposibles por la mayor parte del tajo, garantizándose su inexpugnabilidad con precipicios de hasta $80 \mathrm{~m}$. de desnivel. La comisa natural, mencionada anteriormente, a modo de paso aéreo, es el único acceso practicable al abrigo que, de esta forma, se convierte en un emplazamiento inhóspito, lejos de estar asociado a unpunto concreto de asentamiento humano. Efectivamente, en sus inmediaciones, no se han encontrado restos materiales arqueológicos de ningún tipo, considerando las inmediaciones como la zona junto al tajo.

El paisaje que controla las visuales que se contemplan desde tas cercanías del abrigo dominan perfectamente el cuadrante SW, estando marcada la línea de horizonte por las cotas de las sierras de Albayate, Horconera, Rute, Gallinera, Carcabuey y, en las proximi dades, Sierra Alcaide.

\section{IV.2. Contenido temático y tipológico}

Para ladesignación de tipos, vamos a seguir la clasificación de Acosta (Acosta, 1983) por ser la más empleada, aunque señalando que, del asignar una forma a un tipo, no se puede extraer su significado como motivo aislado, y mucho menos en relación con otros, al menos en la mayoría de los casos. Por otra parte, el considerar un tipo como la suma de atributos más significativos nos parece positivo por cuanto no nos lleva a una compartimentación excesiva.

Motivo 1 y 3: trazos o barras simples (arqueadas).

Motivo 2: antropomorfo en doble Y.

Motivo 4: oculado o ídolo simple (según BARROSO RUIZ, 1983, oculado del grupo I, tipo I -junto a los de Vacas de Retamoso, Murciélagos y Murcielaguina)-.

Motivo 5: ancoriforme (con uno de sus brazos más prolongado y el otro terminado en trazo horizontal).

Motivo 6: ramiforme.

Motivo 7: antropomorfo de piernas y brazos en ángulo (estos últimos levantados).

Motivo 8,9,10: puntos.

Si partimos de que las pinturas representan un lenguaje y si éste, para ser comprendido, precisa ser público y por tanto necesita de un "aprendizaje", un tiempo, que explique las similitudes y también las diferencias regionales (como nos recuerda MARTÍNEZ GARCÍA, 1981), los paralelos, ya no sólo de los motivos aislados sino de las composiciones, asociaciones o agrupaciones, nos podrían dar una pista a seguir.

En este sentido antropomorfos de brazos levantados, dentro de su gran variedad, tenemos en: Farallón Tomajona, abrigo del Santo, Lavaderos de Tello, Vacas de Retamoso, Sierrezuela, el Escorialejo, covatilla de San Juan; Vereda de la Cruz (en relación, varios, con cruciformes); cueva de la Araña, cueva del Queso, Palomas (asociado a 
ramiformes); cueva del Plato, Navalcán, La Graja (junto a puntos); Julio Martínez (uno asociado a un cuadrúpedo y otros dos -de distinto tamaño- a un antropomorfo); cueva de los Paradores (dos, uno con sexo y otro sin sexo); Chinchilla (dos junto un trazo y puntos); Cañada de Corcuel (junto a cápridos y antrop. en doble Y).

Tipo golondrina tenemos en Murcielaguina, C. Colorada, Saladavieja, Bacinete, cueva Mediodía del Arabi; c. Victoria (muchos junto a círculos, con trazo vertical 1 que lo divide por la mitad, y un posible oculado); Murciélagos (junto a cápridos); Molaina (4 juntos); Cimbanillo de M' Antonia (3 junto a antrop. en phi griega); Lavaderos de Tello ( 2 junto antrop. en doble y). Ramiformes en la Graja, Palomas, Prado de Azogue, cueva de los Arcos; Barranco de los Arcos (Junto un oculado); cueva del Queso (junto antrop. de brazos levantados); Palomas (varios juntos).

Oculados, presentes tanto en cerámica como hueso y piedra (ver SORIA LERMA y LÓPEZ PAYER, 1986-87), en contextos calcolíticos, aunque considerados como deidades procedentes del Neolítico (para JORDA, 1983 del fondo cultural Epipaleolítico) relacionablesconelculto de fertilidad. Tenemos oculados en Vacas de Retamoso, Peñas de Cabrera, Barranco de la Niebla, cueva de los Arcos, cueva del Pajarraco, abrigo de Laja Alta, la Cimbarra, collado del Guijarral; Murciélagos (junto zoomorfo); Murcielaguina (varios junto a antropomorfo); Barranco de los Arcos (junto aramiforme); Diosa Madre (tres, para TAMAIN, 1986 se trataría de un posible observatorio astronómico). Muchos de estos oculados parecen ocupar un lugar destacado dentro de los soportes pictóricos. Antropomorfos endoble Y los encontramos en la Mella, Barranco de la Cueva; Navalcán, Cañada de Corcuela (junto a antropomorfos); Tabla de Pochico (junto antrop. y zoomorf.); Lavaderos de Tello (con ancoriforme). Trazos y puntos aparecen en multitud de lugares, indicar, respecto de los primeros, Murcielaguina, Garganta de la Hoz, Abejera, Piedra del Sestero; Barranco de Estoril (asociados a soles) y, respecto de los segundos, Morcielaguilla de la Cepera o los abrigos de Jimena de la Frontera.

Vemos que el resultado, al menos en una primera aproximación, no es muy alentador y creemos no poder alcanzar a ver los motivos con entidad dinámica. Se nos ofrece un panorama especial de distribución, pero no un "ente" vivo que se interrelaciona con otros y varía según el tiempo". (MARTÍNEZ GARCÍA, 1981:62).

Parece, pues, como si los motivos tuvieran significado en sí mismos y variable según la relación con otros, pero, en principio, no por una asociación admitida, convencional, con unas regias, sino, quizás, una especie de pre-escritura simple, o más simple de lo que creemos, en donde la asociación de motivos, generalizada, no existe.

\section{3. Estado de conservación, pigmentación y técnica}

Las pinturas, en la oquedad donde se trazaron, han perdurado hasta hoy gracias a la combinación de una serie de factores. 
Protegidas de la incidencia directa del agua de lluvia por su posición elevada en el abrigo, ésta tampoco ha podido dañarlas indirectamente al deslizarse, por gravedad, a lo largo de la pared de roca, pues una pequeña cortina natural lo impide. De esta manera, el color del abrigo es rojo-anaranjado mientras que el resto del roquedo de los alrededores, salvo excepciones, es azul intenso debido a la oxidación, alteración climática sufrida y a la invasión de musgos y líquenes.

Obviamente, el abrigo fue seleccionado antes de pintar en él, mostrándosenos como un lugar perfectamente definido en el que se realiza una obra, en este caso pictórica, que se desea perdure el mayor tiempo posible.

$\mathrm{Su}$ orientación al lado del poniente, ha librado a la pintura de estar sometida a prolongados calentamientos por la incidencia directa de la luz solar, durante muchas horas al día, lo que unido a las temperturas nocturnas más bajas podría haber provocado un desprendimiento, por descamación, de la superficie rocosa primitiva. A pesar de todo, la descamación superficial de la roca es el factor que ha contribuido en mayor medida a la mala conservación puntual de algunos de los motivos pictóricos. En otras ocasiones, la misma pintura es la que se ha desprendido del soparte rocoso.

El estado de conservación de los diferentes motivos, salvo el $n^{\circ} 6$ y los puntos aislados $8,9,10$, lo podemos considerar de bueno y aceptable, con nula o escasa patinación caliza (observable sobre todo en los motivos 6 y 7). El color empleado en todos ellos es el' 'rojo vinoso" (2) a excepción del $n^{9} 5$, anaranjado, y el n ${ }^{\circ} 6$, granate oscuro, aunque en una tonalidad próxima a la figura $\mathrm{n}^{9} 7$. Cabe pensar que los tonos más claros puedan deberse a una incidencia de los rayos solares a una hora más temprana pues el lado derecho del abrigo sólo recibe el sol, menos intenso, de la tarde. Puede haber, sin embargo, multitud de razones y ya desde antiguo (BREUIL, 1929) se barajaba (a posibilidad de que, en ocasiones, las diferencias de tono de los colores empleados pueda deberse a la degradación desigual de un mismo pigmento por causas naturales o por la acción del hombre, y no al empleo de un preparado pictórico diferente.

No obstante, es posible que la teoría del color y la conservación diferencial de los motivos aporten datos de interés sobre la contemporaneidad simultánea de los mismos.

El motivo $n^{9} 5$ presenta tonos tan anaranjados que no es probable que se tratara con el mismo preparado pictórico con el que se pintaron la mayor parte de las figuras. En la

(2) "El problema de la denominación uniforme de los colores por todos los investigadores está por resolver, aunque existe una propuesta de ta reunión de Barbastro para unificarlas. Las diferencias de matices provocadas no só!o por el pigmento utilizado sino, además, por la degradación del color, la pintura y otros elementos superpuestos, la hora, sequedad o humedad del ambiente y estación de la observación y, cuando se trabaja sobre diapositivas o fotografías, la diferente reacción frente a los colores de los diferentes clichés (amarillento de Fujichrome. azulado de Ektachrome, exageración de los colores de Kodachrome falta de brillantez de ellos de! Agfachromc. etc.) aparte de haber sido obtenidas mojando las pinturas o no, provocan que los rojos oscuros, vinosos, amoratados, carmines etc. se nombren con ja imprecisión que puede imaginarse, sin que pueda resolver la cuestión cualquier índice del tipo Mumscll para las tierras (Mumsell Sysiem Color Notaiion, New York 1954) puesto que el proWerna está en la identificación del color en cada caso". (Según APARICIO, J. el alii, 1988: 117). 
gradación de un color existen diversas tonalidades que ofrecen desde la máxima saturación a la mínima, próxima al blanco. En la gradación del color que hemos convenido en llamar aquí rojo vinoso, no existe ningún tono próximo al naranja pues, para conseguir éste, hace falta el empleo de colores ocres.

Con todo esto, planteamos la posibilidad de que, al menos el motivo ${ }^{\circ} 5$, fuera trazado con un preparado que tuviera, como base, mineral de hierro más o menos rico en ocres.

Podremos objetar que la humedad ambienta) puede transformar a la hematíes (tonos rojos) en oligisto (tonos ocres) por hidratación, pero creemos que una meteorización diferencial en los motivos pictóricos del Tajo de Zagrilla es improbable, dadas las características del abrigo.

En cuanto al motivo $\mathrm{n}^{\circ}$ 6, éste se encuentra muy desdibujado, ofreciendo una conservación deficiente, claramente diferenciado del resto de los motivos. Si lo suponemos simultáneo de los demás, es difícil creer o buscar una justificación de su deterioro (dejando a un lado la acción antrópica), pues todas las pinturas habrían estado sometidas a los mismo factores de deterioro y prácticamente en la misma intensidad. Si hubo repintes de algunas de las figuras, éstos no son apreciables hoy día. Cabe la posibilidad de que fuera trazado en otro momento y que su deterioro se deba más a una diferencia en los componentesde la pintura(aglutinante+mineral).Unaevaporización demasiado rápidao muy violenta del agua del aglutinante (ya fuera simplemente agua o grasa animal o vegetal) podría haber motivado una excesiva pulverización del pigmento, que se desprendería con facilitad del soporte rocoso.

Referente a las técnicas del diseño de las figuras, hay dos motivos, $\mathrm{n}^{\circ} 1$ y 3 que, con toda seguridad, fueron trazados de arriba a abajo y probablemente de un sólo trazo, pues presentan un engrasamiento e intensidad del color en la parte superior y un estrechamiento en la inferior que es propia de las "pinceladas" realizadas en este sentido. El resto de las figuras, más complicadas, se retocan en varias direcciones. Todas las figuras son, pues, de trazo simple y tinta plana (BALDELLOU. 1989).

La procedencia del mineral de óxido de hierro, base del pigmento, puede ser local, ya que a $8 \mathrm{Km}$. del Tajo se encuentran minas de almagra (Zamoranos y Camponubes) en explotación hasta hace poco tiempo. En los minerales allí extraídos, aparecen tonos que presentan una gama desde el rojo oscuro hasta el anaranjado.

\section{IV, 4. Ámbito geográfico}

S' Alcaide forma parte del macizo de Cabra, entidad geológica de unos $80-100 \mathrm{~km}^{2}$ y altura máxima de $1380 \mathrm{~m}$. (Lobatejo), siendo una de las divisiones tectónicas más características de la Subbética Cordobesa. Su estratigrafía básica la constituye un Trias margoso con yesos y brechas, y las dolomías y calizas, con diferentes caracteres, que vienen constituir el nivel esencial de la karstificación (DÍAZ DEL OLMO et alii, 1989). 
Efectivamente, el relieve de las calizas.con una tectónica típicamente Alpina, domina el paisaje, donde destacan las áreas de sierra, sin cultivar, sólo susceptibles de aprovechamiento agrario extensivo, con un papel destacado de la ganadería caprina.

Las masas rocosas subbéticas son muy permeables debido a su gran fisuración, situando el coeficiente de filtración entre el $75 \%$ y el $85 \%$ del total de precipitaciones (600-800 mm. anuales) que reciben estas montañas (FELGUEROSO, 1967). El desagüe deeste agua es muy efectivo, existiendo una estrecha relación entre el régimen hidrológico de los manantiales y el régimen pluviométrico. El macizo de Cabra es una de las cuencas hidrogeológicas de mayor interés de la Subbética y viene a desaguar las filtraciones pluviales por su base, siendo de menor importancia los manantiales de media altura (ORTEGA, 1975). De este modo, tenemos importantes emergencias en los límites del macizo, estando una de ellas (manantial de Zagrilla) en las cercanías del abrigo donde se localizan las pinturas. Manantiales de distinta índole y localizados a diferente altura (incluso en cotas superiores alos $1000 \mathrm{~m}$ ) jalonan los entornos geográficos de nuestro emplazamiento, que se ven completados con una corriente de agua continua, el río GenillaZagrilla, que discurre al sur de $S^{1}$ Alcaide y cuya vega es apta para la agricultura.

Las condicionantes del binomio vegetación/fauna se han alterado sensiblemente a lo largo de la historia. En general, las partes bajas se sometieron a una roturación intensa ya en época romana (los restos de "villae" en los alrededores de la aldea de Zagrilla no son escasos) que seguirá con una ocupación musulmana que acentuará los regadíos. Todo esto ha motivado que el bosque mediterráneo y el matorral vayan cediendo espacio en favor del olivo y otros cultivos aunque, en las cotas altas, el dominio del encinar residual y el pastizal se mantiene. Los tipos predominantes de especies arbóreas son encinas, quejigos, alcornoques y otras especies del género "Quercus" y, en cotas más bajas, acebuches, álamos, nogales y chopos, siendo los arbustos típicos de la sierra, tomillo, romero, lentisco, jara, retama, zarzamora y otras (GAVILÁN, 1986b-GARCIA, PULIDO, 1989).

La fauna se ha visto, si cabe, más alterada aún y tenemos testimonios sobre la Paleofauna hoy extinta. A principios del s. XIV, p, ej., el Libro de la Montería de Alfonso XI habla de la existencia de osos durante todo el año, en la zona geográfica que nos interesa (LÓPEZ et alii, 1988). Actualmente quedan diferentes especies animales, como rapaces (águila, buitre, buho...) y mamíferos (turón, tejón, gineta...), aunque reseñamos la presencia del jabalí y la cabra montesa (prácticamente extinguida) por sus características cinegéticas.

Podemos concluir, pues, que hasta fines de la E. Media, lacomarca ha gozado de unas características naturales extraordinarias, muy aptas parael asentamiento humano, que se han visto degradadas de forma importante hasta nuestros días (VERA, 1990). Aún, así, buena pane de las subbéticas cordobesas, el Tajo de Zagrilla incluido, se declararon Parque Natural, según Decreto que entró en vigor el 28 de Junio de 1988. 


\section{- Cueva de Detrito y Cerrillo del Torreón del Esparragal}

Dentro del cuadrante NE del Tajo de Zagrilla, la localizamos a unos $750 \mathrm{~m}$. Esta cavidad fue elegida como lugar para realizar, probablemente, un enterramiento al que debieron pertenecer, como panes integrantes del ajuar funerario, los siguientes materiales constatados. Estos consisten, principalmente, en dos formas cerámicas; una espada corta, en bronce, y cuatro remaches en la parte de la empuñadura; un puñal, también en bronce, con siete escotaduras en la zona de enmangue; y varios objetos de silex,raspadory núcleo como piezas destacadas. Todos estos materiales han sido estudiados como pertenecientes al "mundo argárico" (GAVILÁN, MORENO, 1987).

En las inmediaciones de la cueva, en el exterior, se han documentado restos adjudicables cuturalmente al Calcolítico, destacando, por su número, los fragmentos cerámicos. De nuevo en el interior de la cueva de la Detrita y también descritos como Calcolíticos, tenemos fragmentos de cerámicas de borde en grosado.y diverso material en silex, del que destacan por su interés, un raspador sobre hoja, una hoja fragmentada con escotadura y una lasca laminar (GAVILÁN, MORENO, 1987).

\section{- Cueva del Muerto}

La localizamos también, a escasos kms. del lugar que nos interesa, en el cuadrante S W y dentro del término municipal deCarcabuey. Esta cavidad ha proporcionado materiales neolíticos (cerámica y hueso trabajado) y otros que encuadran mejor en contextos caleolíticos (hoja de silex de considerable longitud y un "ídolo" de hueso). Los materiales calcolíticos parecen asociados a una sepultura de inhumación (GAVILÁN, 1986a).

\section{- Cueva de los Arrastraos}

Situada en la vertiente SW de $S^{a}$ Alcaide (término municipal de Carcabuey), fue descubierta en 1990 por miembros del G.E.S. Priego. Actualmente en estudio, ofrece materiales diversos que parecen apuntar a una cronología Neolítico Final-Calcolítico. Probablemente conserve inhumaciones "in situ", sin alterar por remociones de tierra modernas.

\section{- Cueva de los Murciélagos}

Este importante yacimiento arqueológico del Neolítico andaluz se encuentra a unos 7250 m. del Tajo de Zagrilla. Lo incluimos aquí, a pesar de quedar más distanciado que el resto de los yacimientos porque el llamado Camino Viejo a Zuheros desde Zagrilla, comienza su andadura a los pies del Tajo. Este camino ha sido utilizado, prácticamente hasta nuestros días, para el trasiego del ganado desde un lado de S- Alcaide hacia otro, aprovechando un collado natural para remontar este macizo, y después continuar en dirección a Zuheros. La distancia entre el Tajo y la cueva de los Murciélagos se puede recorrer en tan sólo unas tres horas. 
Efectivamente, el relieve de las calizas, con una tectónica típicamente Alpina, domina el paisaje, donde destacan las áreas de sierra, sin cultivar, sólo susceptibles de aprovechamiento agrario extensivo, con un papel destacado de la ganadería caprina.

Las masas rocosas subbéticas son muy permeables debido a su gran fisuración, situando el coeficiente de filtración entre el $75 \%$ y el $85 \%$ del total de precipitaciones (600-800 mm. anuales) que reciben estas montarlas (FELGUEROSO, 1967). El desagüe deeste agua es muy efectivo, existiendo una estrecha relación entre el régimen hidrológico de los manantiales y el régimen pluviométrico. El macizo de Cabra es una de las cuencas hidrogeológicas de mayor interés de la Subbéticay viene a desaguar las filtraciones pluviales por su base, siendo de menor importancia los manantiales de media altura (ORTEGA, 1975). De este modo, tenemos importantes emergencias en los límites del macizo, estando una de ellas (manantial de Zagrilla) en las cercanías del abrigo donde se localizan las pinturas. Manantiales de distinta índole y localizados a diferente altura (incluso en cotas superiores alos $1000 \mathrm{~m}$ ) jalonan los entornos geográficos de nuestro emplazamiento, que se ven completados con una corriente de agua continua, el rio GenillaZagrilla, que discurre al sur de $S^{!}$Alcaide y cuya vega es apta para la agricultura.

Las condicionantes del binomio vegetación/fauna se han alterado sensiblemente a lo largo de la historia. En general, las partes bajas se sometieron a una roturación intensa ya en época romana (los restos de "villae" en los alrededores de la aldea de Zagrilla no son escasos) que seguirá con una ocupación musulmana que acentuará los regadíos. Todo esto ha motivado que el bosque mediterráneo y el matorral vayan cediendo espacio en favor del olivo y otros cultivos aunque, en las cotas altas, el dominio del encinar residual y el pastizal se mantiene. Los tipos predominantes de especies arbóreas son encinas, quejigos, alcornoques y otras especies del género "Quercus" y, en cotas más bajas, acebuches, álamos, nogales y chopos, siendo los arbustos típicos de la sierra, tomillo, romero, lentisco, jara, retama, zarzamora y otras (GAVILÁN, 1986b-GARCIA, PULIDO, 1989).

La fauna se ha visto, si cabe, más alterada aún y tenemos testimonios sobre la Paleofauna hoy extinta. A principios del s. XIV, p. ej., el Libro de la Montería de Alfonso XI habla de la existencia de osos durante todo el año, en la zona geográfica que nos interesa (LOPEZet alii, 1988). Actualmente quedan diferentes especies animales, como rapaces (águila, buitre, buho...) y mamíferos (turón, tejón, gineta...), aunque reseñamos la presencia del jabalí y la cabra montesa (prácticamente extinguida) por sus características cinegéticas.

Podemos concluir, pues, que hasta fines de la E. Media, la comarca ha gozado de unas características naturales extraordinarias, muy aptas para el asentamiento humano, que se han visto degradadas de forma importante hasta nuestros días (VERA, 1990). Aún, así, buena parte de las subbéticas cordobesas, el Tajo de Zagrilla incluido, se declararon Parque Natural, según Decreto que entró en vigor el 28 de Junio de 1988. 
Ya hemos comentado que en las inmediaciones del abrigo no se ha encontrado, hasta hoy, ningún objeto de interés arqueológico y que el entorno geográfico es muy apto para elasentamientohumano. Disponemos de una zona con aguaabundanteapesarde la al tura y lo abrupto del terreno, y de un ecosistema que, en su día, era rico en fauna, cinegéticamente utilizable.y vegetación no sólo explotable como base alimenticia de una hipotética ganadería caprina, sino como complemento a la nutrición humana (frutos silvestres en general, encina, nogal, acebuche, zarzamora...), combustible (plantas leñosas) e incluso como recurso médico-natura) con las plantas de propiedades medicinales (GAVILÁN. 1986b). La vega del ríoGenilla ofrece como contrapartida al paisaje serrano, unas tierras fértiles, llanas y muy apropiadas para una agricultura de regadío. Todos estos factores no pasaron desapercibidos al hombre, que nos ha dejado restos de sus actividades en la zona desde, al menos, el Paleolítico Medio.

Concentrándonos en lo que nos interesa, la cronología esgrimida usual mente para el Arte Rupestre Esquemático, parece que tiene sus ejemplos más antiguos en contextos neolíticos y que perdura y se desarrolla durante la E. del Bronce, e incluso, para algunos autores, habría que prolongarla nastael Hierro I (APARICIO etalii, 1988),momentoéste en que dejaría de emplearse este tipo de manifestaciones debido a la aculturación del arte de los pueblos colonizadores. Dentro de este paréntesis cronológico, los yacimientos arqueológicos más relevantes (3) en el entorno geográfico del Tajo de Zagrilla se sitúan, excepto el último mencionado aquí, en S' Alcaide y son:

\section{- Cueva-Sima de Cholones}

Se encuentra a tan sólo 1300 m (4) al SW del lugar de las pinturas. En Cholones existen pinturas rupestres esquemáticas que ya fueron publicadas por FORTEA y BERNIER(1970).

Los materiales neolíticos documentados en esta cavidad (GAVILÁN 1987), se pueden incluir dentro de un Neolítico Medio y Final, con diversos útiles de silex, piedra y hueso trabajados, elementos de adorno y cerámica, de la que destacamos la incisa y la decorada a la almagra. Como Calcolítico, registramos un pequeño ídolo cruciforme, realizado en piedra, que bien pudiera haber formado parte del ajuar funerario de un enterramiento colectivo (GAVILÁN, 1987). También de Cholones procede un recipiente cerámico en írma de casquete esférico, con paredes exteriores bruñidas (GAVILÁN, 1987).

(3) La mayoría de los objetos de interés arqueológico a los que se alude a continuación, se encuentran depositados en el Museo Histórico Municipal de Priego de Córdoba.

(4) Las distancias expresadas de aquí en adelante, se han trazado en linca recta, sobre el Mapa Topográfico Nacional. Se trata de distancias reducidas, no reales. 
que sepamos, enterramientos de los que nos interesan (Murcielaguina...).

Si encontramos, por el contrario, su asociación a zonas de agua, de paso o de cierto interés cinegético o agrícola de explotación extensiva o a modo de rozas (valles estrechos o piedemonte). De este modo, las pinturas nos pueden hablar de territorios homogéneos, "fronteras", que dentro de un colectivo cultural común defiendan idiosincracias particulares de diversos grupos ("fronteras" debidas a la presión sobre la tierra cultivable y al surgimiento de nuevas relaciones sociales).

En cuanto al significado particular de) panel pictórico del Tajo de Zagrilla nos encontramos de lleno con la cuestión más espinosa. Abordado el tema desde un nivel preiconográfico, tenemos un motivo que, por su tamaño y por su actitud de brazos levantados, puede dirigir; bien la escena, si de eso se trata, o bien el significado último de lo representado.

Buena parte del resto de los motivos se interpretan como antropomorfos. Si esto es correcto, ¿por qué se representa la figura humana con tantas variantes morfológicas? Si no lo fueran, la mayor parte de las interpretaciones actuales serian erróneas. Aludimos con este planteamiento a la servidumbre del significado de los motivos a los intereses de cada investigador. La ecuación antropomorfo-árbol es muy frágil y sus diferentes partes se manejan según intereses interpretativos.

No obstante, sean o no antropomorfos los motivos a los que nos referimos, la figura humana de brazos levantados parece ser hegemónica. Las diferentes figuras no están asociadas entre sí, por lo que puede que no nos encontremos ante una escena' 'cinematográfica' ', teatral, sino ante un mismo mensaje alrededor del que giran varias plasmaciones que no, necesariamente, hubieron de trazarse de forma con temporáne a -simultánea en el tiempo. Con esta idea, el mensaje último de las pinturas ya estaría expresado con las primeras figuras, a las que se podrían añadir otras que redundarían, sin modificar, el mensaje expresado en un primer momento. En cuanto al ídolo oculado, éste parece tener entidad propia y siempre se ha interpretado así. En nuestro caso, ocupa una posición central en el panel, aunque geométricamente no destaque. Para continuar interpretando la singularidad de las pinturas del Tajo de Zagrilla, habríamos de remontarnos al campo iconográfico primario, donde definitivamente podríamos destacar unoferente (si aceptamos que este personaje existía en los actos y cultos primitivos) y un oferido (oculado) que se viene asociando a la divinidad promotora de la Fertilidad. El resto de los motivos representarían personas o grupos humanos, o bien aspectos que, de todas formas, estarían relacionados con esos individuos.

El verdadero significado (nivel iconográfico profundo) es el que nos está vetado. Tenemos signos o cosas de las que se habla, con un código, un medio de comunicación, un emisor y un receptor, pero no alcanzamos los códigos de significaoión. 


\section{6 Propuesta de protección}

En cuanto el Museo Histórico Municipal de Priego de Córdoba tuvo constancia del descubrimiento de las pinturas del Tajo de Zagrilla (verano de 1990), remitimos un informe detallado ala Delegación Provincial de Córdoba, a laque se le daba cuenta de las características de la nueva estación de arte rupestre. En este mismo informe, se sugería la puesta en práctica de medidas de protección que garanticen la integridad del conjunto en el futuro. En la respuesta dada por la Delegación, con fecha 8de Agosto de 1990, se refiere que está pendiente la elaboración de un programa de protección y que se estudian las propuestas realizadas. Esperamos que estas medidas no se demoren pues, como es lógico, desde el momento en que se descubrieron existe el peligro deque la intervención humana descontrolada acelere su destrucción.

El lugar es de complicado acceso lo que, hasta cierto punto, es garantía de seguridad. La presencia humana en el mismo Tajo ha sido muy escasa hasta la fecha, como lo demuestra el hecho de que exista un nido de ave migratoria en el mismo abrigo donde están las pinturas, pero en un lugaren que la acción de las aves (aleteos, defecaciones...) no atenta contra las pinturas. El interior del abrigo se encuentra, igualmente, libre de musgos y líquenes lo que beneficia, en gran medida, su conservación.

El problema se plantea, pues, y sin lugar adudas, con las posibles visitas incontroladas al lugar que, de forma poco afortunada, decidan tocar o mojar las pinturas (5). Creemos que dadas las reducidas dimensiones del abrigo, una reja sería una solución poco costosa y cómoda, ya que permite la contemplación de las figuras pintadas y evita el contacto físico directo con ellas. Una placa metálica grabada podría informar al hipotético visitante del interés arqueológico del lugar, con ánimo de prevenirle adecuadamente sobre lo que en esos momentos está viendo, puesto que consideramos que una correcta información puede conseguir una concienciación del visitante neófito, algo que no se consigue con la instalación simple y llana de un enrejado que, para algunos, puede llegar a ser, incluso, una provocación.

(5) Nosotros consideramos un alentado contra el arte rupestre el mojar unas pinturas, para mejorar la saturación del colorido en la fotografía. Aún en el caso de emplear agua desmineral izada/destilada, un secado desafortunado puede provocar daños irreparables, sobre lodo, en las pinturas en mal estado y poco visibles que son, como es lógico y por desgracia, con las que más frecuentemente se emplea este método. Como ejemplo, mojar con aguas duras una pintura provoca que, después de la evaporación, los pigmentos se queden patinados por carbonato calcico, debido al elevado porcentaje de bicarbonato calcico que lleva en disolución este tipo de aguas. De la misma forma, humedecer unas pinturas cuando la evaporación que se espera es muy lenta (durante el otoño y el invierno generalmente, o en un abrigo situado en la umbría o escasamente soleado) puede favorecer la proliferación de musgos y liqúenes. Con la temperatura baja ( $\mathrm{p}$. ej. durante los anticiclones invernales) se corre el riesgo de congelación del agua que, al aumentar de volumen, desprende la superficie laminada y agrietada del soporte rocoso. 
ACOSTA. P. (1968): La Pintura Rupestre Esquemática, Mein. Sem. Preh. Arq. 1, Universdidad de Salamanca.

(1983): "Técnicas, estilo, temática y tipología en la pintura rupestre esquemática hispana", Zephyrus 36.

ALCINA FRANCH, J. (1989): Arqueología antropológica, Ed. Akal Universitaria, Madrid, 13-25.

ASQUERINO. M.D. (1985):' 'Cerámicas pintadas de lacueva de Mármoles", Separata del XVIICMA,, Logroño 1983, Zaragoza.

(1987a): "El Neolítico en Andalucía. Estado actual de su conocimiento", T.P.: 63-85.

(1987b): "Plaquetas grabadas neolíticas de la cueva de los Mármoles", Separata del XV///CJVA, Islas Canarias 1985, Zaragoza: 239-246.

BALDELLOU, V. (1989): "II Reunión de prehistoria aragonesa: La terminología en el arte rupestre post-paleolftico", Bolskan 6, Huesca.

BARROSO RUIZ, C. 1980: "Nuevas pinturas rupestres en Jimena de la Frontera (Cádiz). Abrigo de la Laja Alta", Zephyrus 30-31:23-43.

BARROSO RUIZ, C. y MEDINA LARA, F. (1981): "Avance al estudio de las pinturas esquemáticas de las peñas de Casabermeja (Málaga)", Zephyrus 34-35:269-284.

BARROSO RUIZ, C. (1983): "Tipología de ídolos oculados en la pintura rupestre en Andalucía". Zephyrus 36:131-135.

BELTRAN, A. (1989): Ensayo sobre el origen y significación del arte prehistórico, Ed. Universidad de Zaragoza, Zaragoza.

BERNIER, J. y FORTEA, J. (1968-69):" Nuevas pinturas esquemáticas rupestres en la provincia de Córdoba. Avance a su estudio". Zephyrus 19-20; 143-164.

BERNIER, J. y otros, (1981): Nuevos yacimientos arqueológicos en Córdoba y Jaén, Publicaciones del Monte de Piedad y Caja de Ahorros de Córdoba, Córdoba.

BLOCH, M. (1989): Ritual Power and Prenistory, Bradley, R./Gardier, J. (Eds.), Cambridge.

BOSCH GIMPERA, P. (1965): "La chronologie de Tan rupestre seminaturaliste et schemátique et la culture megalithique portugaise". Revista da facultades de letras 9 . Lisboa.

BRADLEY, R. (1987): "Time regained: the creatín of continuity", Journal ofthe British Árchaeological Association 140: 1-7.

BREUIL, H. y BURKITT, M. (1929): RockpaintingsofsouthernAndalusia Oxford.

BREUIL, H. (1933-35): Le x pe tritures rupestres schemátiques delaP. Iberique, T. IIV, Langny.

CABRÉ. J. y HERNÁNDEZ PACHECO, E. (1914): "Avance al estudio de las pinturas prehistóricas delextremo sur de España",Trabajosdela Comisiónde investiga- 
clones Paleontológicas y Prehistóricas 3, Madrid.

CARRASCO RUS, J. y PASTOR MUÑOZ, M. (1980): "Nuevas aportaciones para el conocimiento de la cronología de i as pinturas rupestres esquemáticas en Andalucía oriental. El Abrigo de Cariada de Corcuela (Mocito-Granada)",Ze/)AyniJ 30-31;107-,115.

CARRASCO RUS, J. y MEDINA CASADO, J. (1980): Las pinturas rupestres del Cerro de la Pandera-Jaén. Aproximación al fenómeno esquemático en el subbético Giennense, Publicaciones del Museo de Jaén 5.

CARRASCO RUS, J. y CASTAÑEDA NAVARRO, (1981a): "Las pinturas esquemáticas del abrigo de la Higuera (Otiñar-Jaén)", A.PL.., 16:319-342.

CARRASCO RUS, J. MEDINA CASADO, J. LÓPEZ PAYER, G.M. y SORIA LERMA, M. (1981b): "Las pinturas rupestres esquemáticas de Navalcán (Noalejo). Nuevos datos para la arqueología giennense' $\backslash$ Grupo de Estudios prehistóricos. Memoria de actividades (La Carolina-Jaén) 2:29-38.

CARRASCO RUS, J. $y$ PASTOR MUÑOZ M. (1981C): "Avance al estudio de las pinturas rupestres esquemáticas de laCueva del Plato. Panel A (Otiñar-Jaén)", Zephyrus 32-33: 167-185.

CARRASCO RUS, J.; CARRASCO RUS, E.; MEDINA CASADO, L; TORRECILLAS GONZÁLEZ, J.F. (1985): El fenómeno rupestre esquemático en la cuenca alta del Guadalquivir I. Sierras Subbéticas, Prehistoria Giennense I, Granada.

CASTAÑEDA, P. y CARRASCO RUS, E. (1979): "Nuevos datos sobre el esquematismo rupestre apropósito de las pinturas de la "piedra del letrero" de Huescar-Granada", Estudios dedicados a Callejos Serrano. Universidad de Cáceres: 187-198.

COLES, J.M. y HARDING, F. (1979): The Bronze Age in Europe, Methuen Co. Ltd., Londres.

CRIADO BOADO, F. (1990): "Arqueología del paisaje y espacio megalítico en Galicia", Seminario sobre Arqueología Espacial 12, Teruel: 61-119.

DAMS, Let. M. (1979): "L'Abri de los Ciervos (Benalup de Sidonia-Cádiz)", Bulletin de la Societe Prehistorique deL'Ariege 20-14:73-89.

(1980): "Figures inedites du reseau de las Grajas, cáveme de la Pileta (a Benajoán.Málaga)" Travaux de L'Institut D'ArtPrehistorique 22,Toulouse: 189-200.

DÍAZ DEL OLMO, F.; LHENAFF, R; BAENA, R; ALVAREZ, G; MOLINA, J.; VERA, A.L., (1989): "El Karst del Macizo de Cabra y el travertino de Priego de Córdoba", Reunión Karsts Mediterranées.

FELGUEROSO, C. y COMA, J.E., (1967): "Estudio hidrogeológico de parte de la provincia de Córdoba", Bol. Inst. Geol. Min. de España. T. 78, Madrid.

FORTEA, F.J. y BERNTER, J., (1973): "Las pinturas esquemáticas de la cueva de Cholones en Zagrilla (Priego de Córdoba)", XICMA. Zaragoza, 1970:298-301.

FERNANDEZ MIRANDA, M. (Ed.) (1987): El origen de la Metalurgia en la P. Ibérica, Fund. Ortega y Gaset, Un. Compl. de Madrid. 
GARCÍA SÁNCHEZ, M. Y PELL1CER, M. (1959): "Nuevas pinturas esquemáticas rupestres en la provincia de Granada", Ampurias 21:165-182.

GARCIA SÁNCHEZ, M. y SPAHNI.J.C. (1958): "Grabados rupestres esquemáticos de época eneolítica en Baños de Alicum", A.PL. 7: 121 -133.

GARCÍA, F. y SÁNCHEZ. C, (1979): "Una curiosa muestra de arte rupestre en la "cueva de los muñecos" (Santa Elena-Jaén)," XV CN.A. Lugo, 1977, Zaragoza: 483493.

GARCÍA, J.M.. PULIDO, A., (1989): "Valores naturales de las sierras subbéticas", Adarve 315, Priego de Córdoba.

GAVILÁN, B. (1985): "Alisador grabado procedente de la cueva de Murcielaguina (Priego de Córdoba)", Ifigea, 2: 173-176.

(1986a):" ídolo de hueso de la Cueva del Muerto (Carcabuey-Córdoba), E.P.C. 1:71 75, Córdoba.

(1986b): Priego de Córdoba en la Prehistoria. El Neolítico., Ed. El Almendro, Córdoba.

(1986-87): "ídolo cruciforme de la cueva sima de Cholones (Zagrilla, Priego de Córdoba)", Ifigea 3-4, Córdoba.

(1987a): "Nueva plaqueta grabada encontrada en lacueva de los Mármoles de Priego de Córdoba", E.P.C. 3:59-63.

(1987b): Los materiales de la Prehistoria de Priego de Córdoba, Exorna. Diputación Provincial de Córdoba, Córdoba.

GAVILÁN, B y MORENO, A,, (1987): "Avance sobre el enterramiento argárico de la cuevade la Detrita (Priego de Córdoba) ",.XVIII C.N.A, Isla Canarias, 1985, Zaragoza.

GONZALEZNAVARRETE,J.(1971): "Más figuras rupestres en Jaén: lacuevade la Diosa Madre", Publicaciones del Museo de Jaén iI, Jaén.

HARRIS, M,,(1987): Caníbales y Reyes. Los orígenes de las culturas, Ed. Alianza, Madrid.

JORDA, F. (1983): "Introducción a los problemas del arte esquemático de la P. Ibérica",Zphyrus 36:7-12.

KÜHN, H. (1957): El arte rupestre en Europa, Barcelona.

LEWIN, R. (1989): La interpretación de losfósiles, Ed. Planeta, Barcelona.

LÓPEZ PAYER, M.G. y SORIA LERMA, M. (1980):' 'Las pinturas rupestres de la Cueva Grande de el Puntal (Jaén)",Zephyrus 30-31:73-87.

(1984-1985): * 'Las pinturas esquemáticas rupestres del Barranco de Doña Dama (La Carolina-Jaén), ArsPraestóricaT.III-IV.

LÓPEZ, A.; VALLE, B.; GARCÍA, F,, (1988): "Caza y paisaje geográfico en las tierras héticas según el libro de la Montería", Actas V Coloquio Internacional de $H^{a}$ Medieval de Andalucía, Córdoba.

MARQUEZ ROMERO,J.E.yMORALES MELERO, A.(1985): "Prospecciones su- 
perficiales en S Camorra (Molina-Málaga)", Anuario Arqueológico de Andalucía T. II: 29-30.

MARTIN DE GUZMAN, C. (1981): "Nociones epistemológicas y arqueología prehistórica", I Jornadas de Metodología de Investigación Prehistórica: Soria 1981, Madrid, Ministerio de Cultura: 35-63.

MARTÍNEZ GARCÍA, J. (1981): "El conjunto rupestre de la Rambla de Gergal (Gergal, Almería). Nuevos descubrimientos y apreciaciones cronológicas", C.P.U.G. 6: 35-73.

MARTÍNEZ GARCÍA, J. (1984-85) "Un nuevo abrigo con pintura rupestre en Maimón, Velez- Blanco (Almería)", Ars Praestórica T. m-IV: 279-285.

MARTÍNEZ NAVARRETE, M.J. (1989): Una revisión crítica de la Prehistoria española. La Edad del Bronce como paradigma. Ed, Siglo XXI, Madrid.

MAS i CORNELLA, M. (1986-1987): "Grabados de la cueva del Arco. Conjunto rupestre del Tajo de las Figuras y del abrigo del Tajo de Albarranes (Medina Sidonia, Cádiz)", ATL. 5-6:243-252.

MORALES MELERO, A. y MÁRQUEZ ROMERO, J.E., (1984): "Las pinturas esquemáticas malagueñas y sus relaciones con culturas materiales", Arqueología Espacial, 3:175-195.

OBERMAIER, H. (1919): El hombre fósil, Madrid.

ORTEGA ALBA, F. 1975: El sur de Córdoba. Estudio de Geografía Agraria. T.I. Monte de Piedad y Caja de Ahorros de Córdoba, Córdoba.

RAMOS, J.; ESPEJOM.M, y CANTALEJO, P. (1989): "Arte Rupestre Esquemático en el Alto Velez. El abrigo de Marchamonas", Revista de Arqueología 99:12-18.

RENFREW, C. (1979): Before civilization: The radiocarbon revolution andprehistoric Europe, London, Penguin Books.

(1988): * 'En busca de una arqueología científica", Revista de Occidente 81:77-97.

RJPOLL, E. (1983): 'Cronología y periodización del esquematismo prehistórico en laP. Ibérica",Zephyrus 36:27-35.

ROVIRA, S. (1990): "'Técnicas de investigación arqueometalúrgica", Seminario sobre ciencia y técnicas al servicio de la investigación arqueológica, Fundación Giner de los Ríos (Madrid), U.A.M.

RUBIO DÍAZ, A. (1976): "Las pinturas rupestres de la cueva Victoria (La Cala, Málaga"), Zephyrus 26-27:233-242.

RUIZ RODRÍGUEZ, A.; CHAPA, T. y RUIZZAPATERO, G. (1988):' 'La Arqueología Contextual: una revisión crítica", T,P. 45:11-17.

SANCHIDRIAN TORTI, J.L. (1982): "ídolos femeninos esquemáticos de la cueva de Nerja", Zephyrus 34-35:103-107.

SHENNAN, S.J. (1989): "Introducción Archaeological aproaches to cultural indentity", One world Archaeology 10. Archaelogical Aproaches to Cultural Identity (Ed. 
Shennan, S.J.), London.

SORIA LERMA.M. (1981): Estudio tipológico y estadístico de los motivos rupestres del Subbético Giennense. Reflexiones en torno a la cronología del Arte Rupestre Esquemático de la cuenca alta del Guadalquivir, Memoria de Actividades del G.E.P. (La Carolina, Jaén) II, Jaén.

SORIA LERMA, M. y LÓPEZ PAYER, M.G. (1986-87): "Los caicos inéditos del collado del Guijarral (Jaéa)",A.P. 5-6:235-245.

TAMAIN, G. (1986): "Pintures schematiques, idoles amotif oculés et archeo-astranomie. Lagrotte de la Diosa Madre en Poyo de los Letreros, Jaén. Fut-elle un observatoire astronomique", /// Congrés National des Societés Savames, Poitiers.

THUILLER, P. (1989): "Epistemología y Romanticismo: El fin de la ciencia", Mundo Científico 90: 432-435.

VERA, A.L., (1990): "El medio físico de la comarca de Priego de Córdoba", Antiquitas, 1:3-8, Priego de Córdoba.

VICENT, A.M,; MUÑOZ, A.M., (1973): Segunda campaña de excavaciones en la cueva de ios Murciélagos, Zuneros (Córdoba) 1969, EA.E. 77, Madrid.

VICENTGARCIA, J.M. (1981): "Fundamentos para la investigación epistemológica sobre Prehistoria", I Jornadas de metodología de investigación prehistórica. Soria, 1981, Madrid, Ministerio de Cultura: 71-87.

(1982): "Las técnicas metodológicas en Prehistoria", T.P. 39:9-53. 


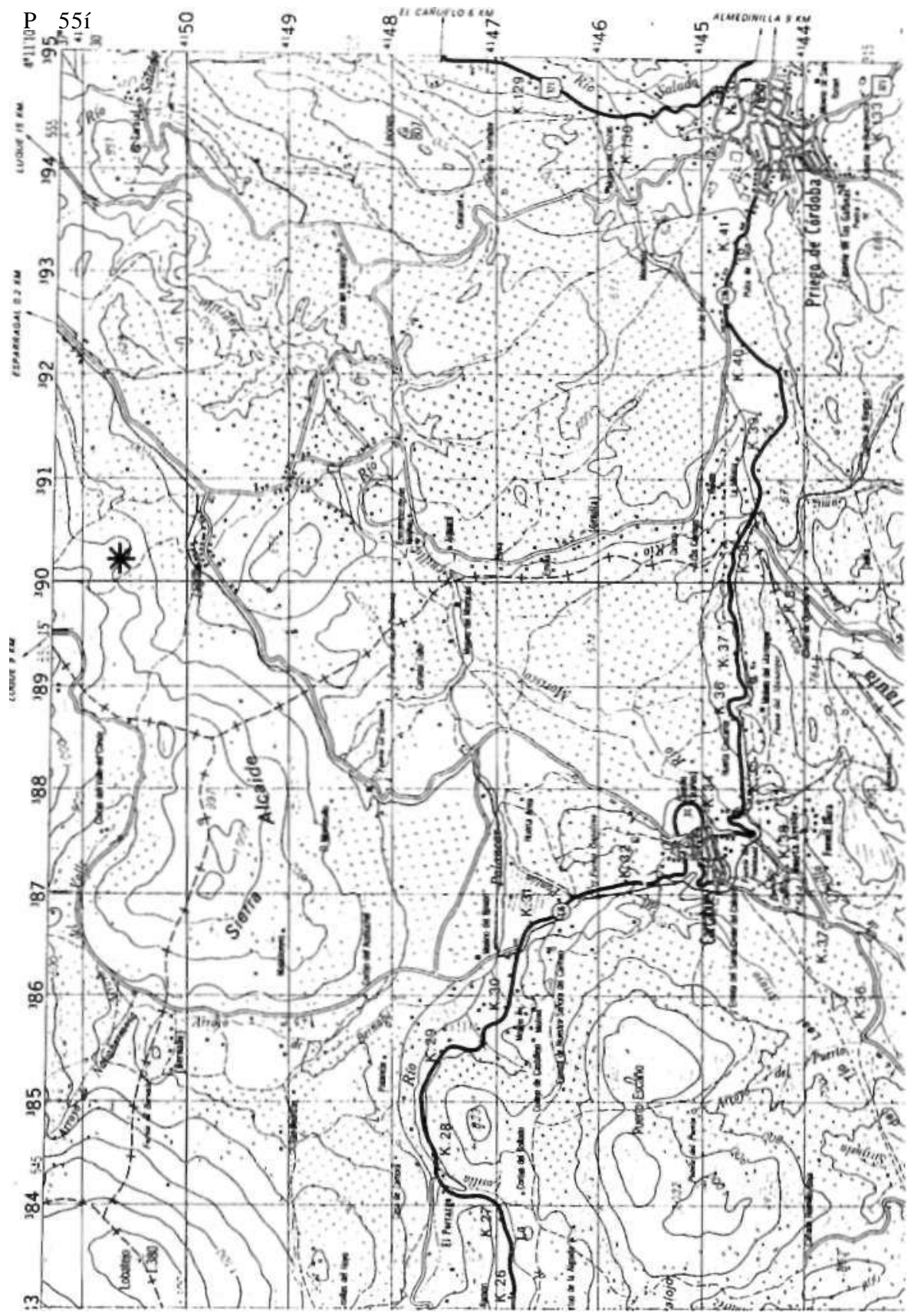

Fig. 1: Emplazamiento geográfico del Tajo de Zagrilla (señalado con asterisco) 


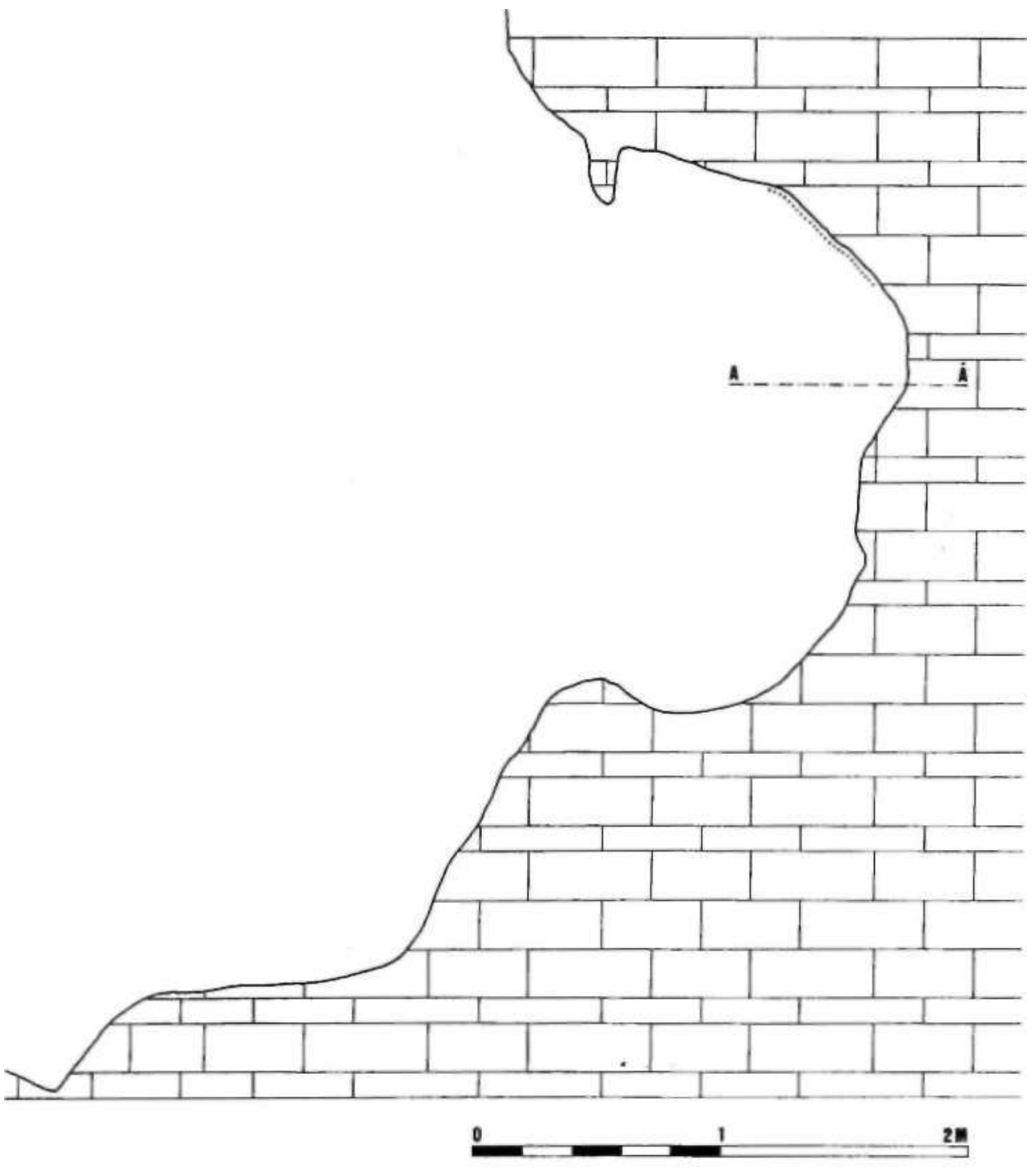

Fig. 2: Sección topográfica vertical del abrigo. La línea de puntos indica el lugar que ocupan las pinturas rupestres. 


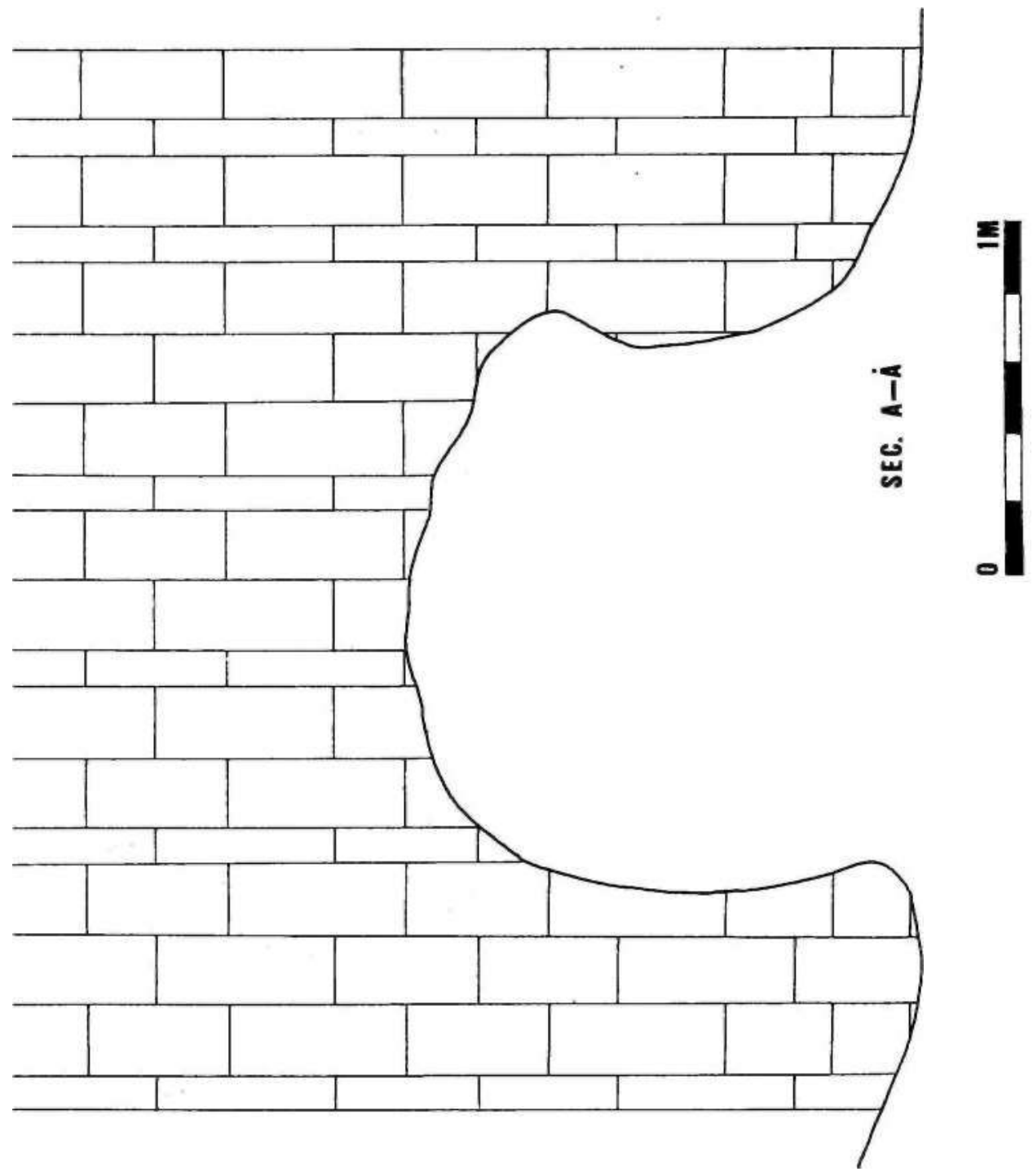

Fig. 3: Sección topográfica horizontal del abrigo. Obsérvense las reducidas dimensiones del mismo. 

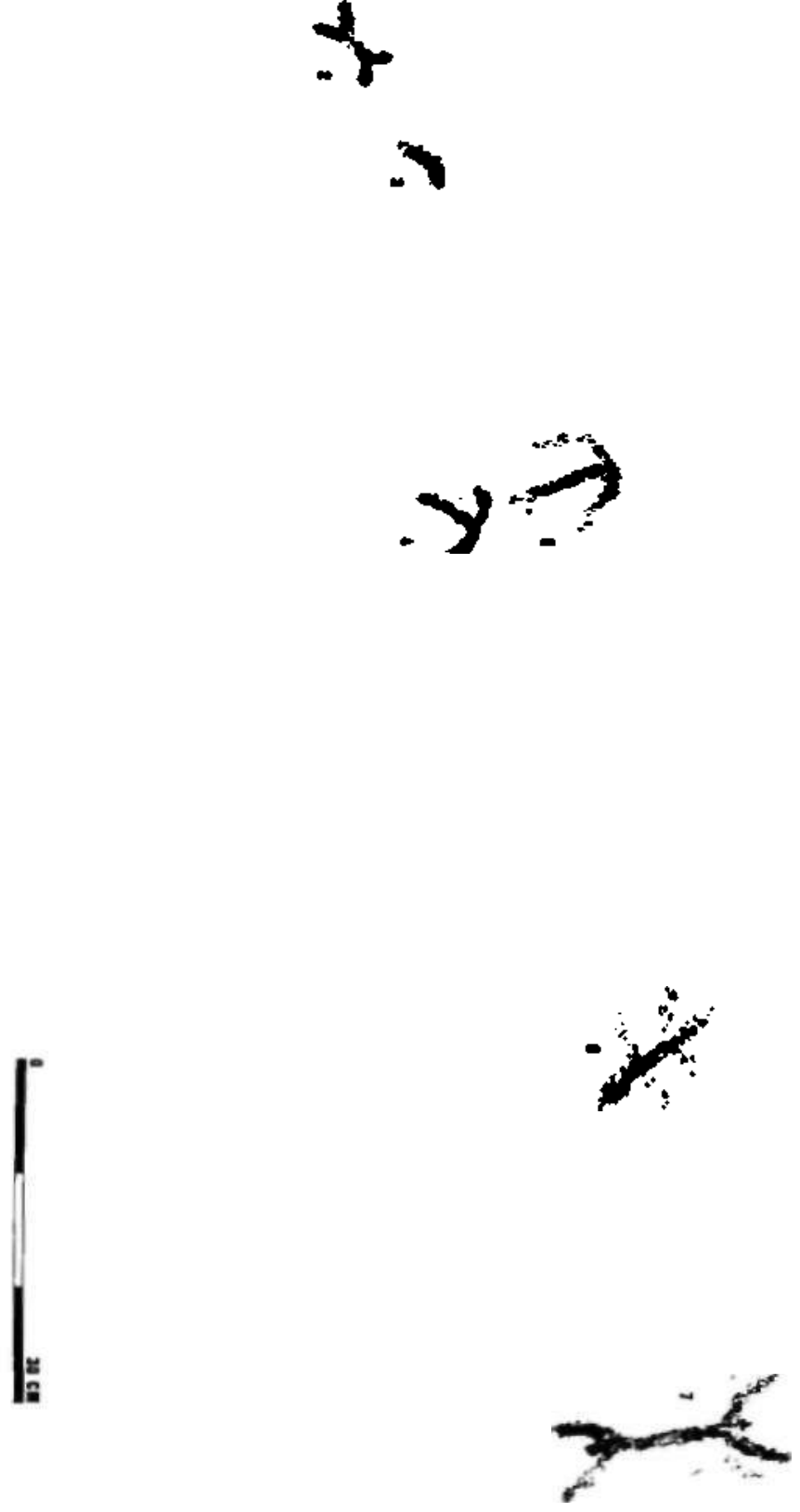

Fig. 4: Disposición de los diferentes motivos en la pared curva del abrigo. Para realizar este calco y para evitar las distorsiones se han empleado, entre las figuras, las distancias reducidas, no reales. 


$$
r^{\prime}
$$



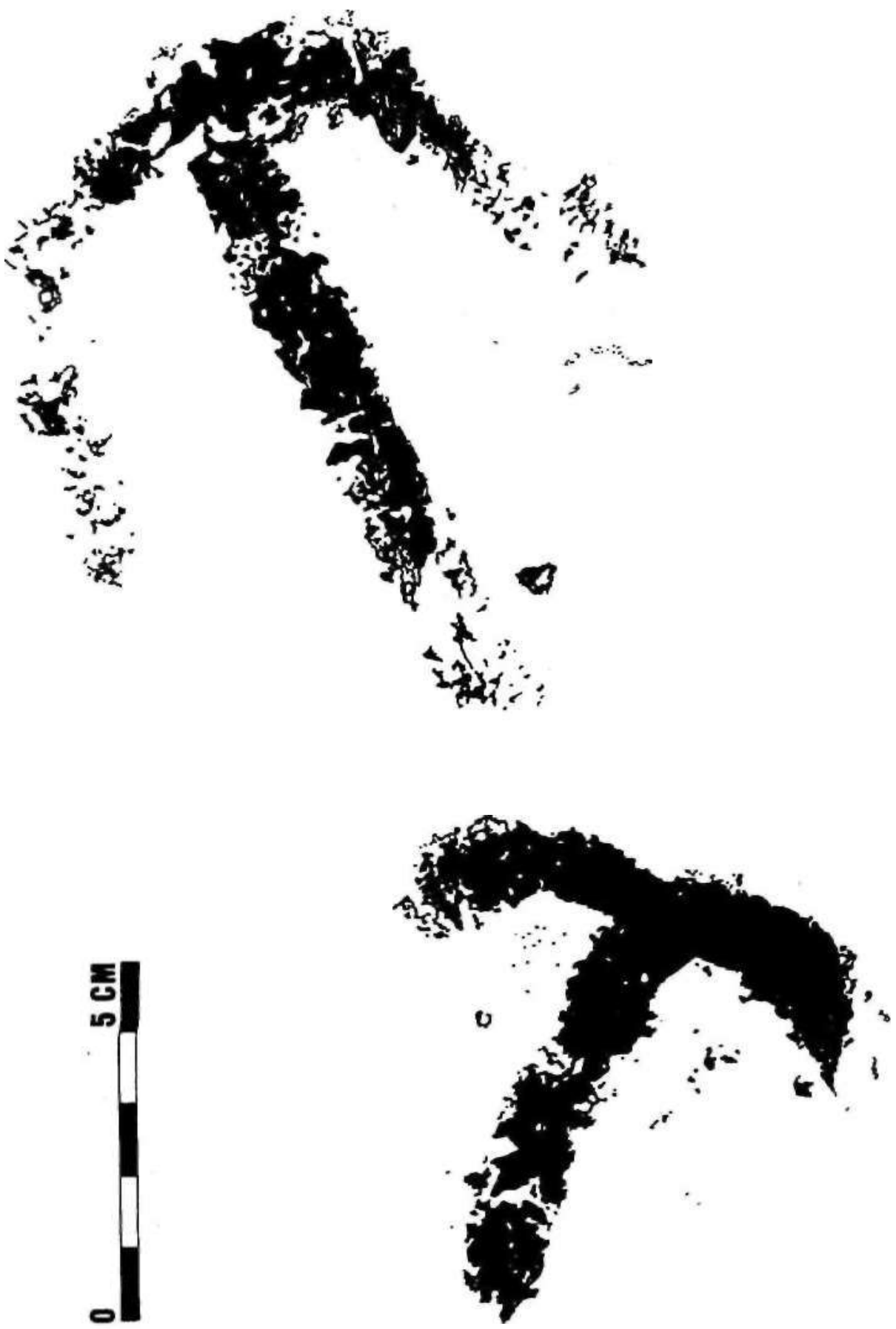

Fig. 6: Motivos 4 y 5. Oculado o ídolo simple y ancoriforme (con uno de los brazos más prolongado y el otro terminado en trazo horizontal. 


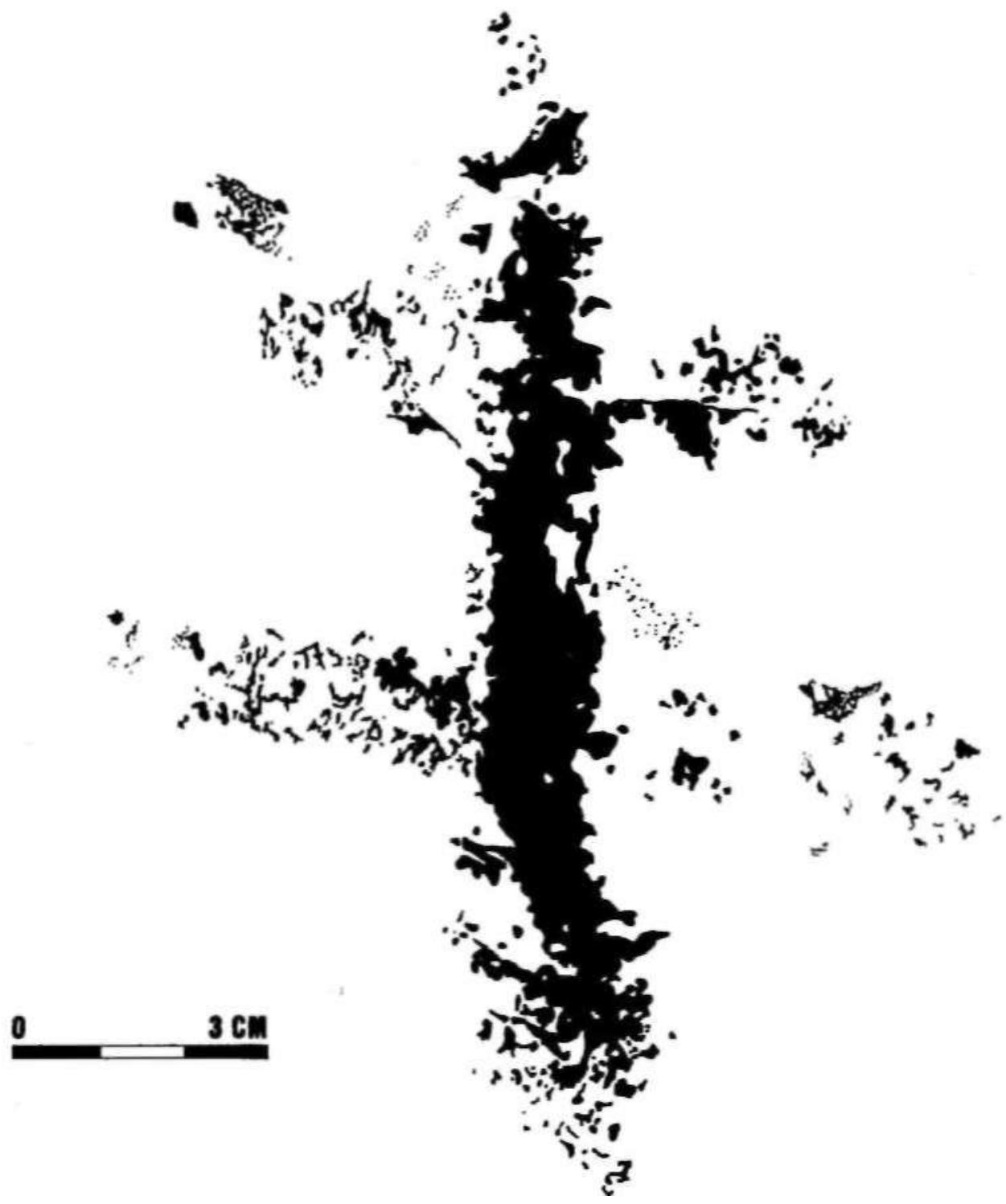

Fig. 7: Motivo 6. Ramiforme. 


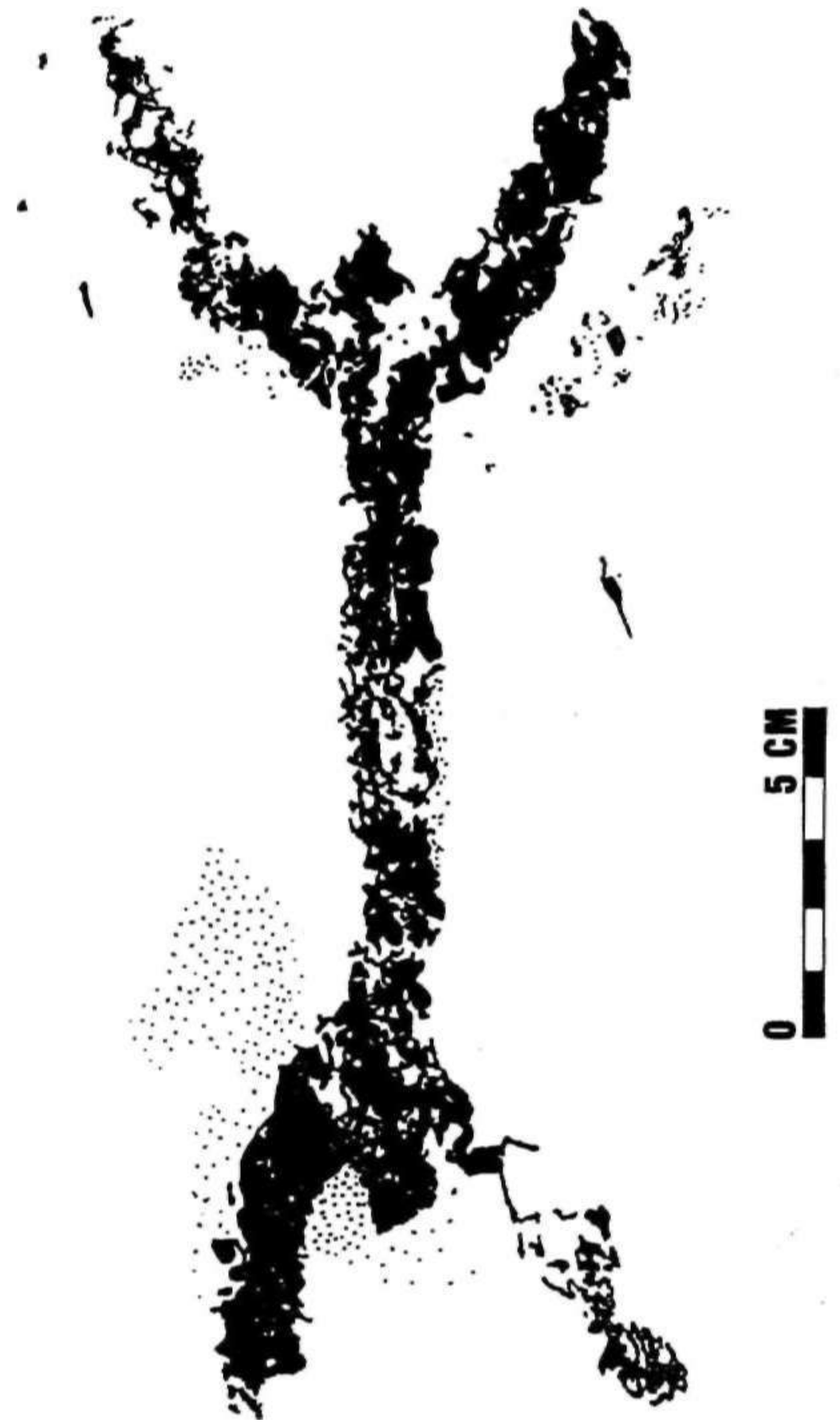

Fig, 8: Motivo 7. Antropomorfo de piernas y brazos en ángulo (éstos últimos levantados). 


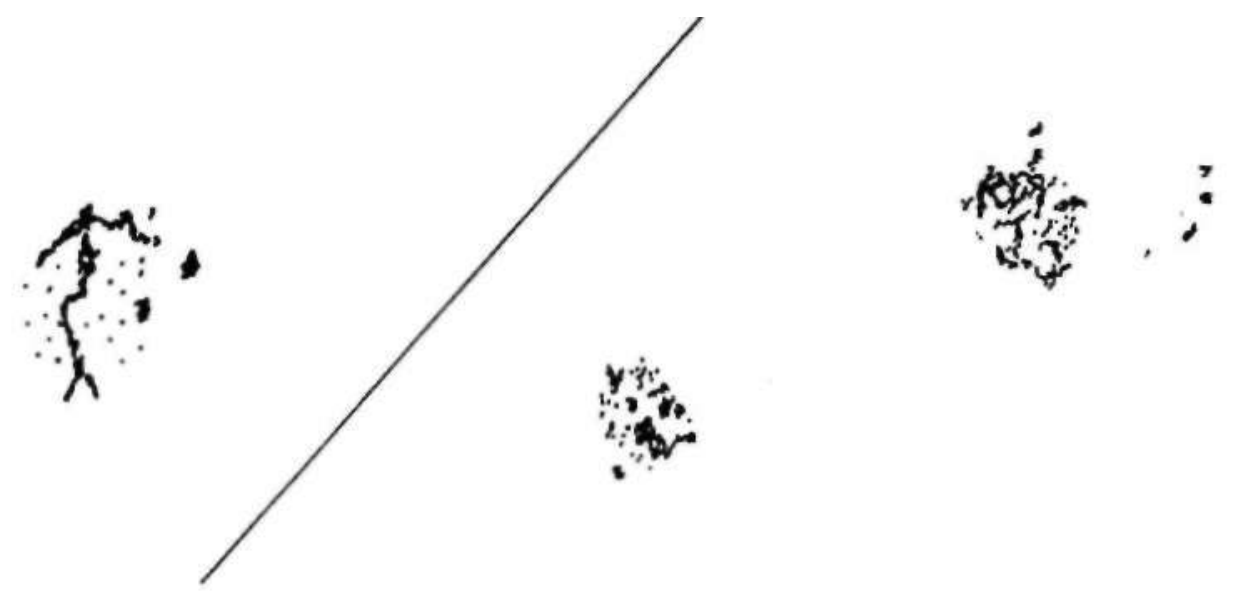

$5 \mathrm{CM}$

Fig. 9: Motivos 8, 9y 10. Puntos o manchas de color. 


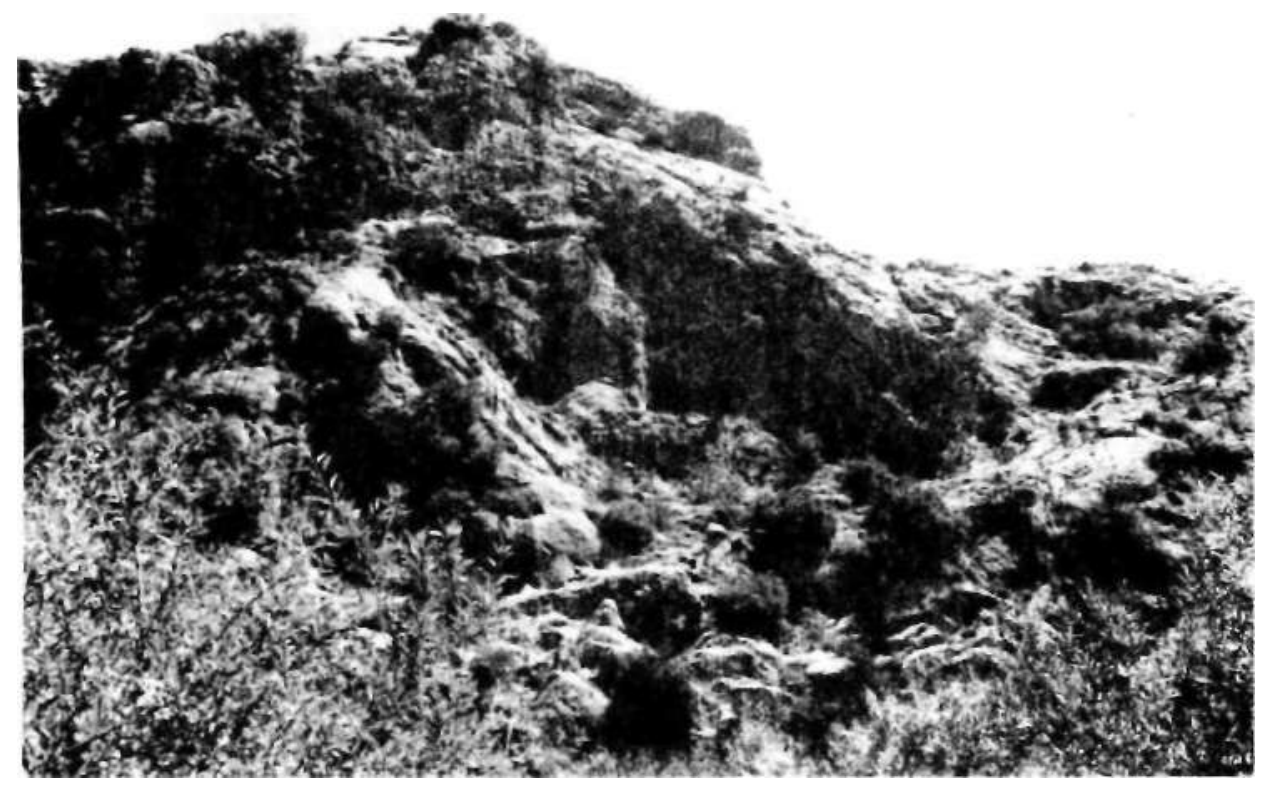

Lam. 1: Panorámica parcial del Tajo de Zagrilla,

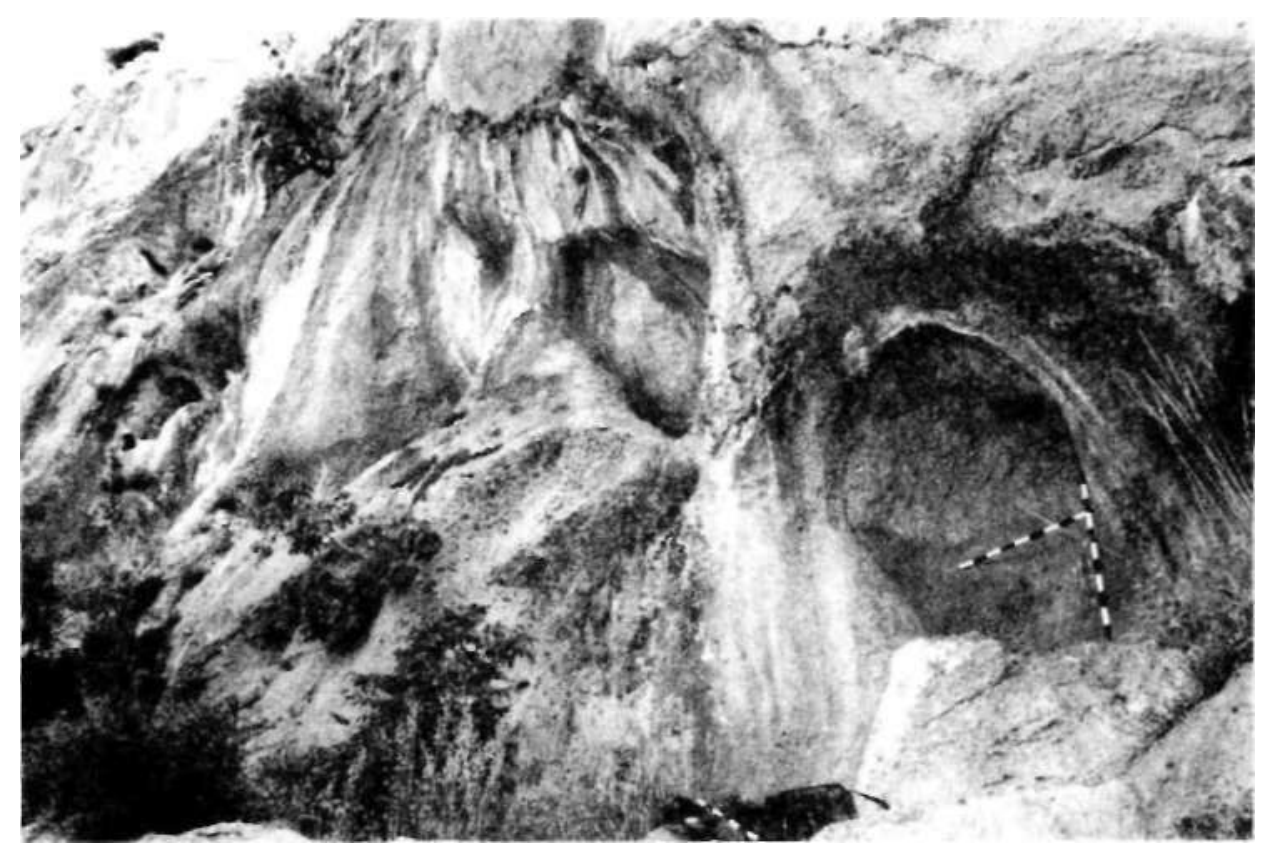

Lam. 2: Vista general del emplazamiento del abrigo de las pinturas (en primer término, con jalones). 


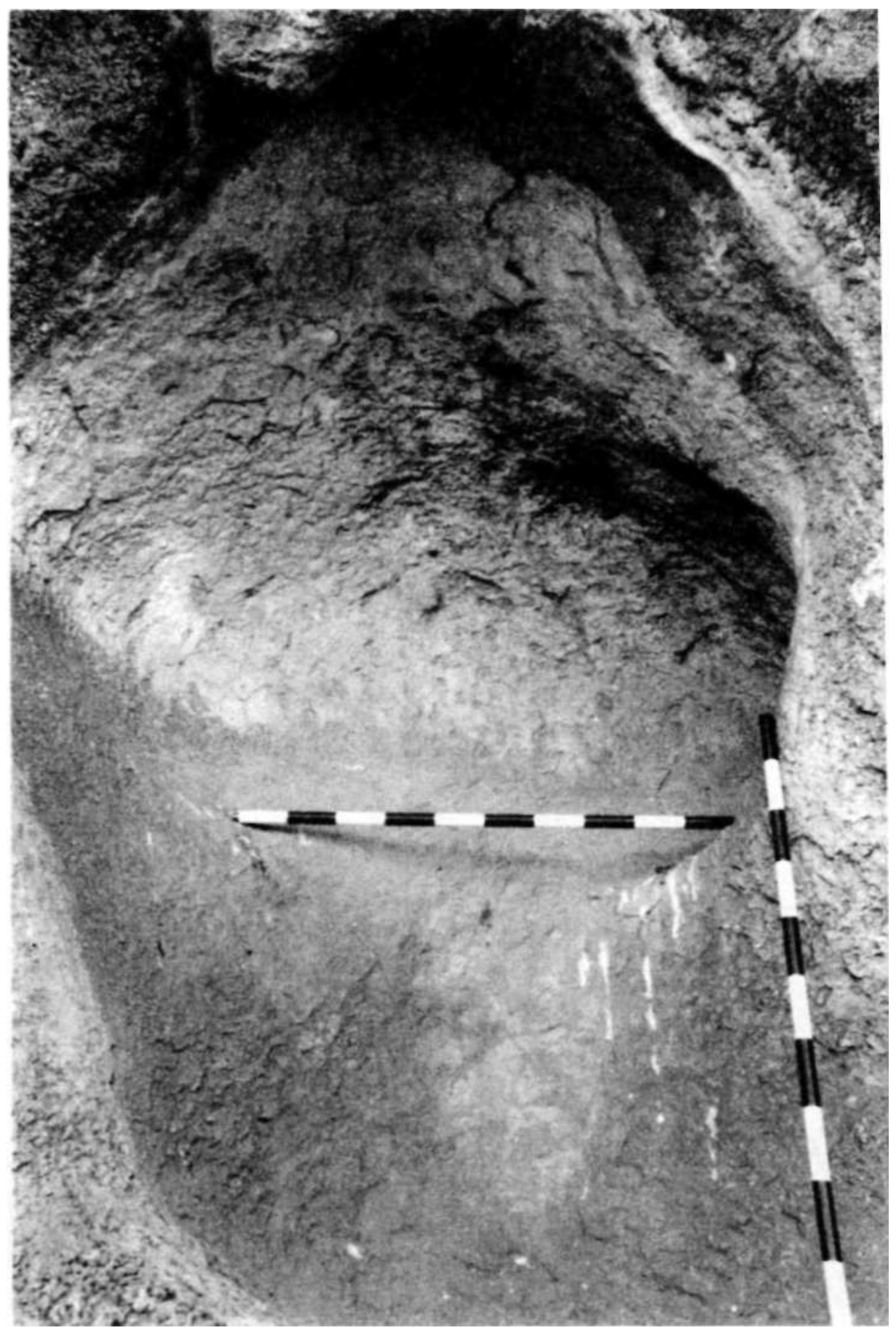

Lam. 3: Abrigo de las pinturas. Detalle. 


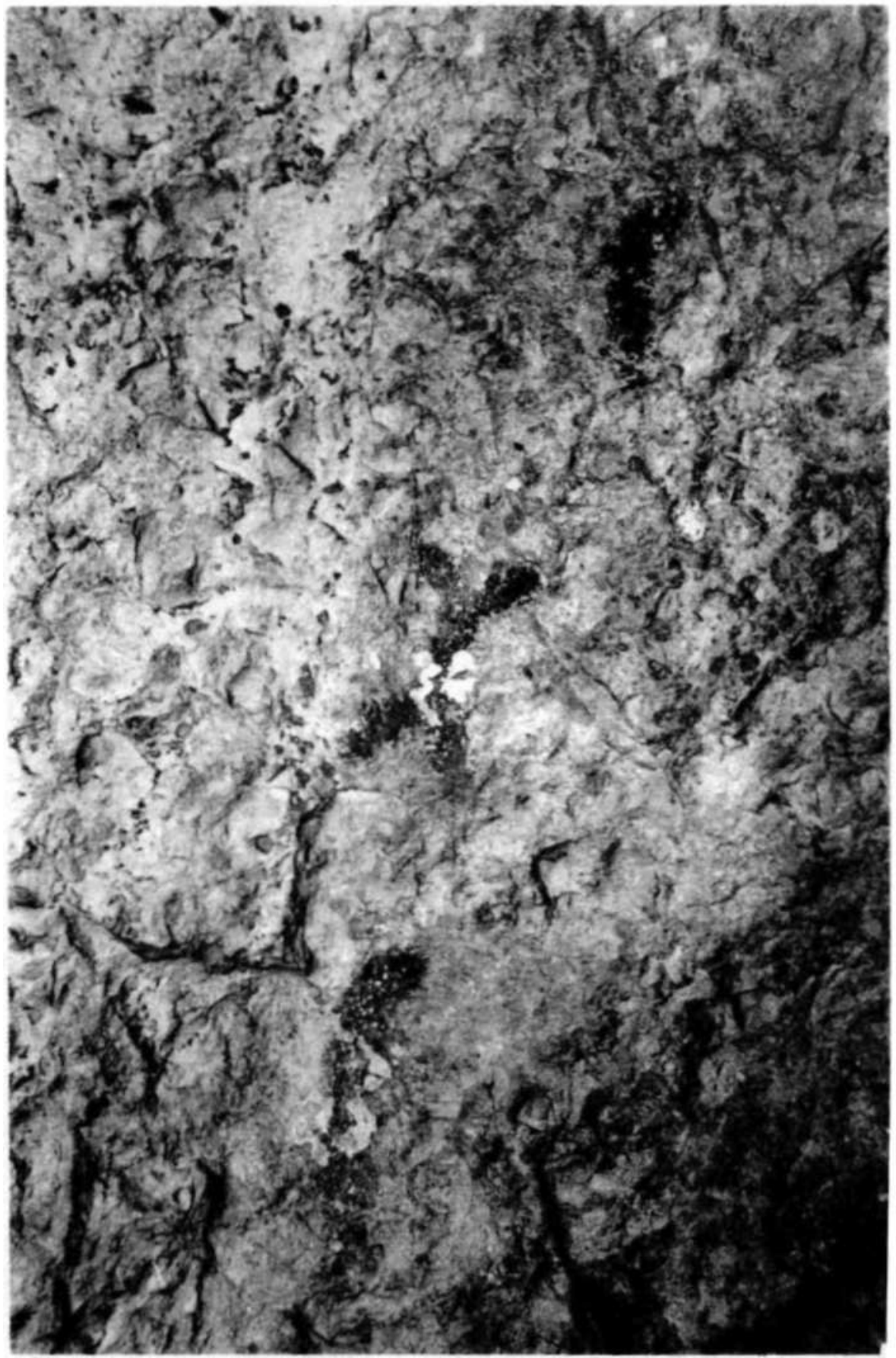

Lam. 4: Motivos 1, 2 y 3. 


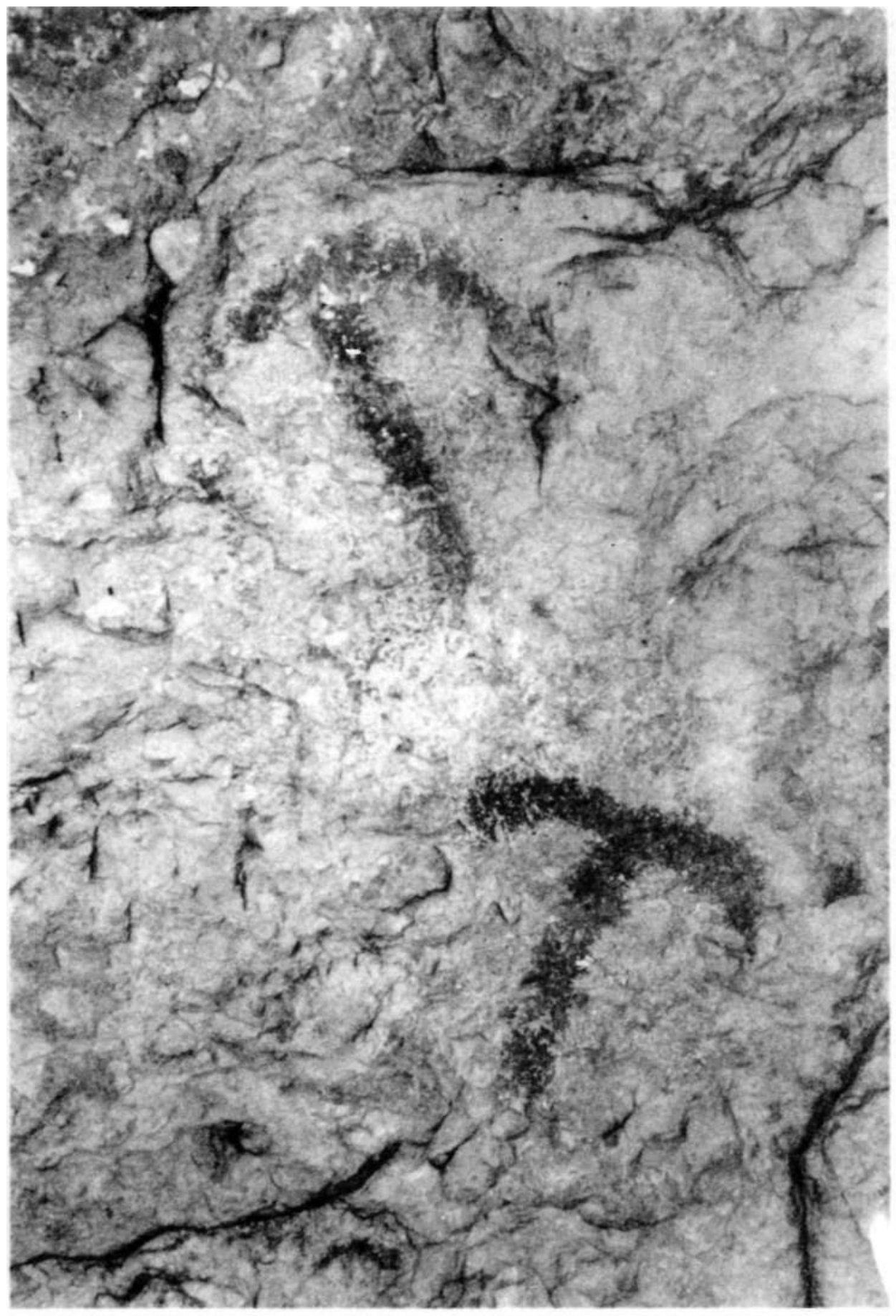

Lam. 5: Motivos 4 y 5. 


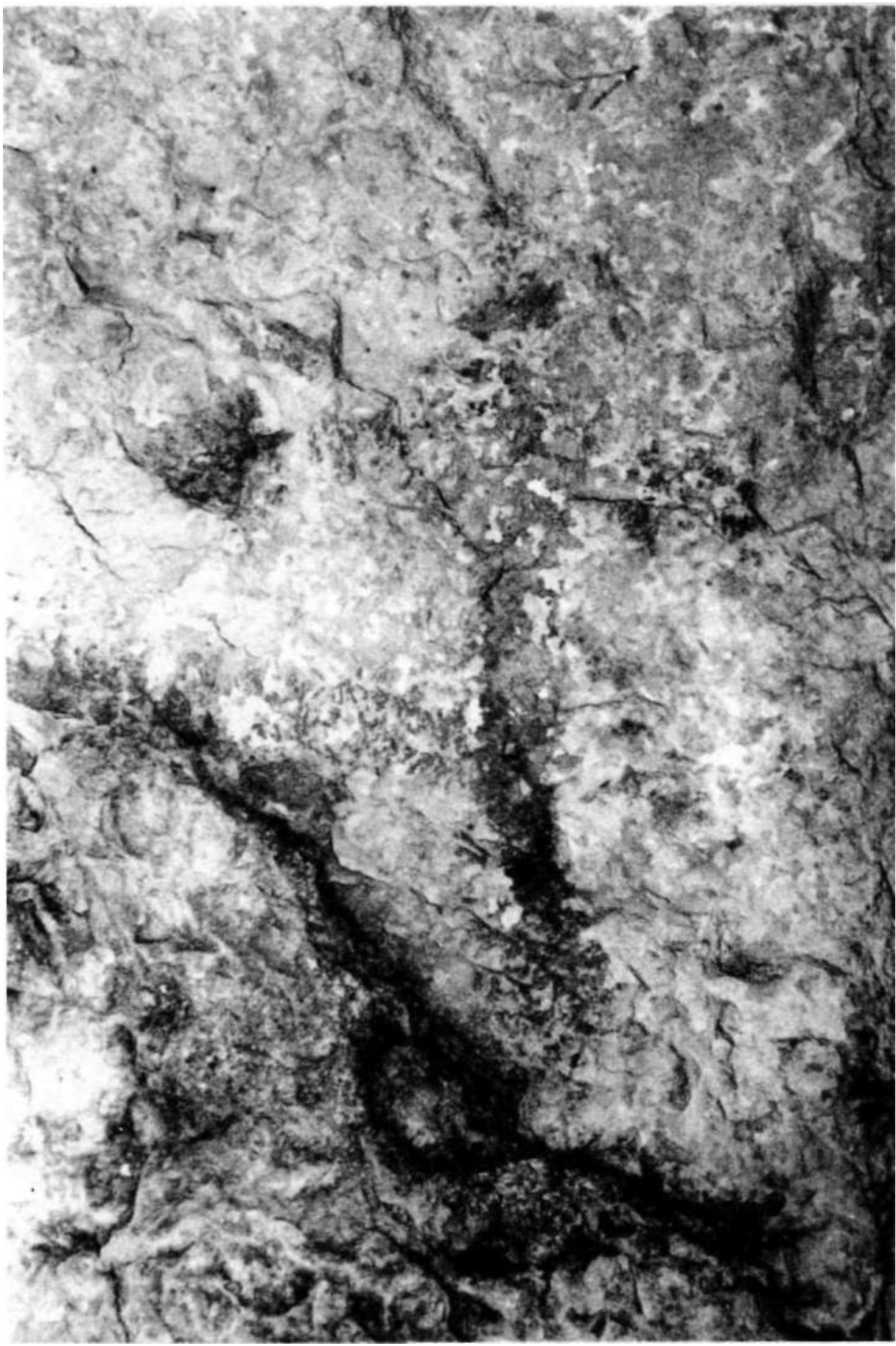

Lam. 6: Motivo 6.

50 


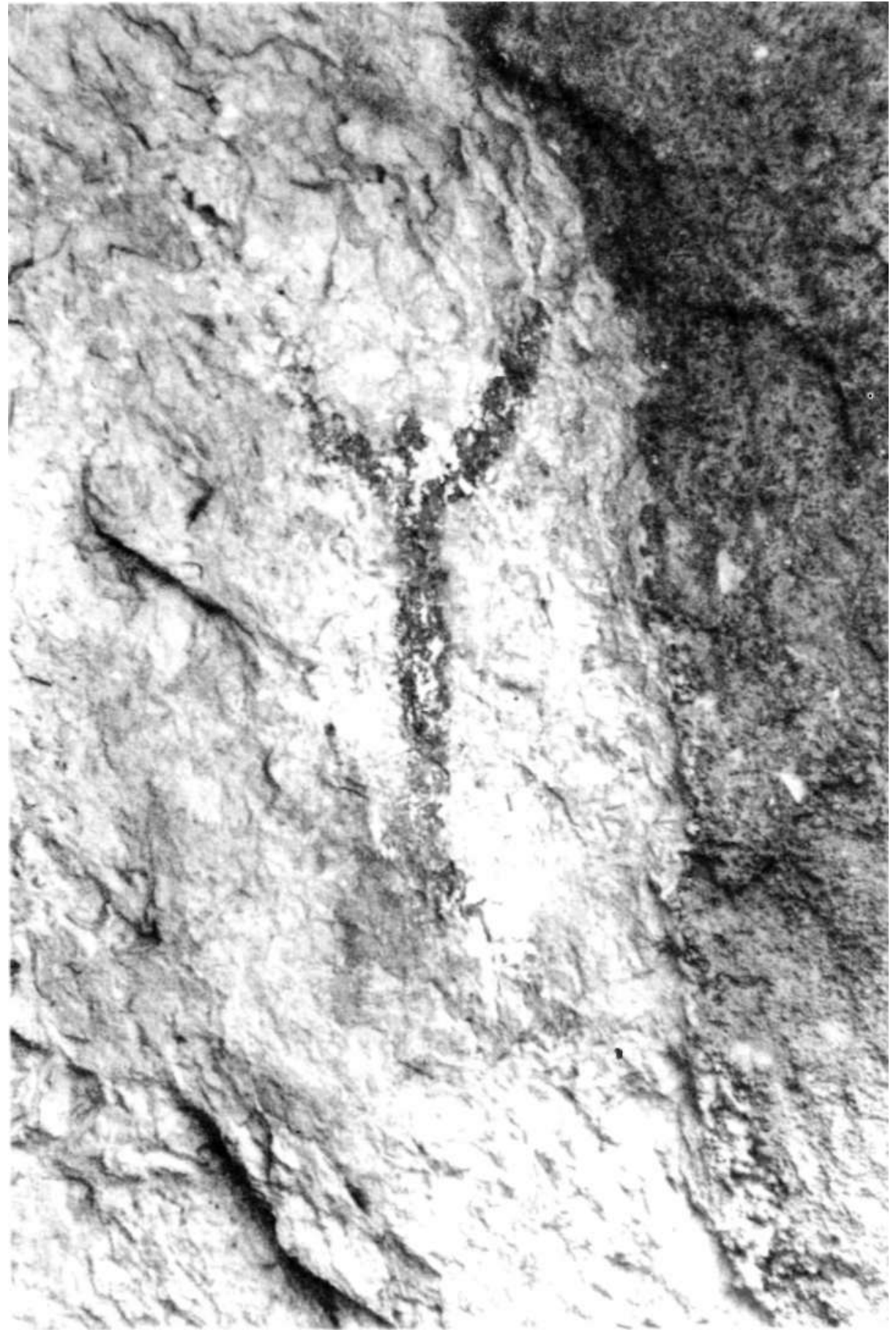

Lam. 7: Motivo 7. 